\title{
RETROFIT WINGLETS FOR WIND TURBINES
}

\section{A Thesis by}

Vijay Matheswaran

Bachelor of Technology, Manipal Institute of Technology, 2013

Submitted to the Department of Aerospace Engineering and the faculty of the Graduate School of

Wichita State University

in partial fulfillment of

the requirements for the degree of

Master of Science

December 2016 
(C) 2016 by Vijay Matheswaran

All Rights Reserved 


\section{RETROFIT WINGLETS FOR WIND TURBINES}

The following faculty members have examined the final copy of this thesis for form and content, and recommend that it be accepted in partial fulfillment of the requirement for the degree of Master of Science, with a major in Aerospace Engineering.

L Scott Miller, Committee Chair

Kamran Rokhsaz, Committee Member

Gaylen Chandler, Committee Member

Syed Raza, Committee Member 
"Out of the sighs of one generation are kneaded the hopes of the next."

Joaquim Maria Machado de Assis (1839-1908) 


\section{ACKNOWLEDGEMENTS}

My deepest gratitude to my advisor, Dr. Scott Miller, for his mentorship, patience, encouragement and countless long talks about airplanes. I am also grateful to the members of my committee, Dr. Kamran Rokhsaz, Dr. Gaylen Chandler and AVM Raza, for their thoughts and feedback at various stages of the study.

Finally, thanks to my parents and sister for their ceaseless love and support. 


\begin{abstract}
Wind energy has demonstrated its potential as a renewable energy source. Much research has been devoted to technologies that improve wind turbine efficiency, winglets being among them. Blade tip vortices increase induced drag and affect wind turbine lift generated. This affects power generated and efficiency of turbines. In aircraft, winglets have proven to reduce induced drag. However, winglets tend to increase wing bending moments, requiring structural reinforcement which could make winglets an expensive proposition.

The primary objective of this study is to design a retrofit winglet for a baseline wind turbine, and determine economic feasibility. Unlike previous winglet designs, an innovative design philosophy has been adopted, attempting to balance aerodynamic forces normal to the winglet surface and generated centrifugal forces by careful configuration design and using lightweight material. Traditional methods to determine power output of a wind turbine, such as the blade element momentum theory, are insufficient to model a wind turbine with winglets. A vortex lattice method for rotor applications has been developed and implemented. Economic feasibility is a key issue in the wind industry today. Accordingly, a cost function that compares design, manufacture and labor costs against increment in power has been implemented.

Using these tools, three winglets with varying construction techniques is investigated. The net result is a winglet configuration that, at minimum installation cost, provides improved performance and economic benefit.
\end{abstract}


1. INTRODUCTION 1

1.1 Introduction and Scope 1

1.2 Objective 3

1.3 Wind Turbine Aerodynamic Modelling 3

1.4 Winglets for Wind Turbines - Prior Studies 5

$\begin{array}{lll}1.5 & \text { Economic Analysis } & 7\end{array}$

2. VORTEX LATTICE METHOD 9

2.1 Introduction 9

$\begin{array}{ll}2.2 \text { Helmholtz's Theorems } & 10\end{array}$

$\begin{array}{ll}2.3 \text { The Biot-Savart Law } & 10\end{array}$

2.4 Application 11

$\begin{array}{lll}2.5 & \text { Method } & 16\end{array}$

$\begin{array}{ll}2.6 & \text { Results and Validation } \\ \end{array}$

3. ECONOMIC MODEL 24

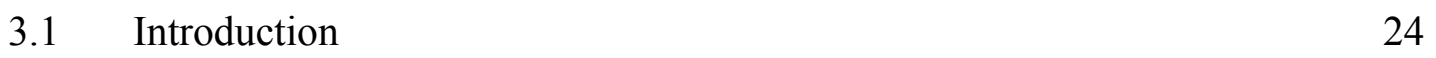

3.2 Cost of Energy 24

3.3 Notes on the Cost of Energy Model 26

3.4 Baseline Cost of Energy for the NREL 5MW Reference Wind Turbine 26

4. RETROFIT WINGLET DESIGN 32

4.1 Design Philosophy 32

4.2 Sensitivity Study 33

4.3 Design A 35

$\begin{array}{lll}4.4 & \text { Design B } & 37\end{array}$

$\begin{array}{ll}4.5 & \text { Design C }\end{array}$

5. RESULTS 42

5.1 Winglet Configuration 42

5.2 Effect on Circulation 46

5.3 Change in Annual Energy Production 46

$\begin{array}{lll}5.4 & \text { Figure of Merit } & 47\end{array}$

$\begin{array}{lll}5.5 & \text { Increase in Thrust } & 48\end{array}$

6. CONCLUSIONS 51

7. RECOMMENDATIONS FOR FUTURE WORK 52

REFERENCES 
TABLE OF CONTENTS (continued)

Chapter

Page

APPENDICES

A. Sensitivity Study

60

B. Basic Structural Analysis

62 


\section{LIST OF TABLES}

Table

1. Top 10 Cumulative Installed Capacity 1

2. Specification of the NREL 5MW Reference Wind Turbine 17

3. Comparison of Results Using Different Methods 21

4. Initial Cost and Operating Expenses of the Baseline NREL 5MW Reference Wind Turbine

5. Annual Operating Expense of the NREL 5MW Reference Wind Turbine

6. Levelized Cost of Energy for the NREL 5MW Reference Wind Turbine

7. Mass Estimate - Winglet A

8. Net Cost - Winglet A

9. Mass Estimate - Winglet B

10. Net Cost - Winglet B

11. Mass Estimate - Winglet C

12. Net Cost - Winglet C

13. Final Winglet Configuration 46

14. Increment in Annual Energy Production 48

15. Return on Investment on Various Winglet Designs 48

16. Effect on Thrust Due to the Use of Winglets 


\section{LIST OF FIGURES}

Figure $\quad$ Page

1.1 New Installed Capacity in MW Worldwide in 2015

2.1 Blade Camber Surface Overlaid with Vortex Rings 13

2.2 Discretized Geometry of the NREL 5MW Reference Wind Turbine with 18 Defined Coordinate System.

2.3 Magnified View of the Spanwise and Chordwise Panels on One Blade 19

2.4 Vortex Lattice Prescribed Wake for a Single Blade 20

2.5 Angle of Attack Distribution Along Blade 22

2.6 Circulation Distribution Along Blade 23

3.1 Weibull Fitted Wind Speed Frequency Distribution for Wichita 29

3.2 Power Curve for the Baseline NREL 5MW Wind Turbine 30

4.1 Freebody Diagram of the Winglet 33

$\begin{array}{lll}4.2 & \text { Winglet Design A } & 37\end{array}$

4.3 Winglet Design B with Al 2024 Connectors at the End of the Winglet 40

5.1 Percent Change in $C_{p}$ Plotted Against the Ratio of Normal Aerodynamic Force to Centrifugal Force for Design A

5.2 Percent Change in $C_{p}$ Plotted Against the Ratio of Normal Aerodynamic Force to Centrifugal Force for Design B

5.3 Percent Change in $C_{p}$ Plotted Against the Ratio of Normal Aerodynamic Force to Centrifugal Force for Design C 46

5.4 Change in Circulation Due to the Addition of Winglets 47

5.4 Figure of Merit $(\Delta C p / \Delta \$)$ Plotted Against the Ratio of Normal Aerodynamic Force to Centrifugal Force for Design $\mathrm{C}$ 


\section{LIST OF ABBREVIATIONS}

\begin{tabular}{ll} 
AEO & Annual Energy Output \\
BEM & Blade Element Momentum theory \\
COE & Cost of Energy \\
CFD & Computational Fluid Dynamics \\
FOM & Figure of Merit \\
FCR & Fixed Charge Rate \\
GW & Gigawatt \\
GWEC & Global Wind Energy Council \\
LLC & Land Lease Costs \\
LCOE & Levelized Cost of Energy \\
LRC & Levelized Replacement Costs \\
MW & Megawatt \\
NREL & National Renewable Energy Laboratory \\
O\&M & Operation and Maintenance Costs \\
VLM & Vortex Lattice Method \\
WER & Wichita State University Wind Energy Report \\
\hline
\end{tabular}




\section{LIST OF SYMBOLS}

$\alpha$

$\phi$

$\Gamma$

$\nabla$

$\delta$

$\theta_{t}$

$\sigma$

$\bar{\Omega}$

$C_{p}$

$\bar{v}_{\text {ind }}$

$\bar{v}_{\infty}$

$\bar{r}$

$\bar{v}_{n}$

$\bar{v}_{t}$

$\bar{v}_{u p d}$

$I_{t}$

$I_{c}$

$M_{t}$

$E_{t}$
Angle of attack

Velocity potential

Circulation strength of vortex element

Gradient/Del operator

Cut-off radius

Blade section twist

Bending stress

Blade rotational velocity vector

Coefficient of power

Induced velocity vector

Freestream velocity vector

Position vector

Normal velocity vector

Tangential velocity vector

Updated velocity vector

Initial cost per year

Initial capital cost

Annual operating expense

Annual energy output 


\section{CHAPTER 1 \\ INTRODUCTION}

\subsection{Introduction and Scope}

In an age where countries are attempting to wean themselves off fossil fuels, wind energy has assumed an important role as a reliable and clean source of renewable energy. From the late seventies to today, wind turbine efficiencies have increased and technologies grown more robust. Rotor sizes have increased several fold, with diameters regularly in the vicinity of over one hundred meters. Wind energy has also, for the most part, been accepted by the public as a dependable source of energy to power the planet. This is evidenced by the steady growth in the global installed wind power capacity over the past two decades.

According to the Global Wind Energy Council (GWEC), the cumulative installed wind capacity worldwide went up from 17,400 MW in 2000 to 432,883 MW in 2015 [1], an astonishing increase of 415,483 MW in fifteen years. Much of this increase has been fueled by a bid to embrace cleaner forms of energy, as well as the development of larger and better designed turbines. Table 1 depicts the top ten total cumulative installed capacities in Megawatts as of 2015. In 2015 alone, new installed capacity totaled $63.46 \mathrm{GW}$, with China, USA, Germany, Brazil and India each significantly increasing their installed capacities. Figure 1 shows the worldwide increase in installed capacities in 2015.

In December 2015, 186 nations signed the COP21 agreements in Paris. The agreements call for a power sector that is $100 \%$ emissions free by 2050 . In the aftermath of the 2015 COP 21 agreements in Paris, the onus rests on renewable energy technologies such as wind and solar energy to play a greater role in powering the planet. Indeed, the exponential growth of wind energy underlines its importance in today's world, and make studies that look to improve efficiency, such as this one, all the more relevant. 
TABLE 1

TOP 10 CUMULATIVE INSTALLED CAPACITIES

\begin{tabular}{|c|c|c|}
\hline COUNTRY & MW & SHARE (\%) \\
\hline PR China & 145,362 & 33.6 \\
\hline USA & 74,471 & 17.2 \\
\hline Germany & 44,947 & 5.8 \\
\hline India & 25,088 & 5.3 \\
\hline Spain & 23,025 & 3.1 \\
\hline United Kingdom & 13,603 & 2.6 \\
\hline Canada & 11,205 & 2.4 \\
\hline France & 10,358 & 2.1 \\
\hline Italy & 8,958 & 2.0 \\
\hline Brazil & 8,715 & \\
\hline
\end{tabular}

Source: GWEC [1]

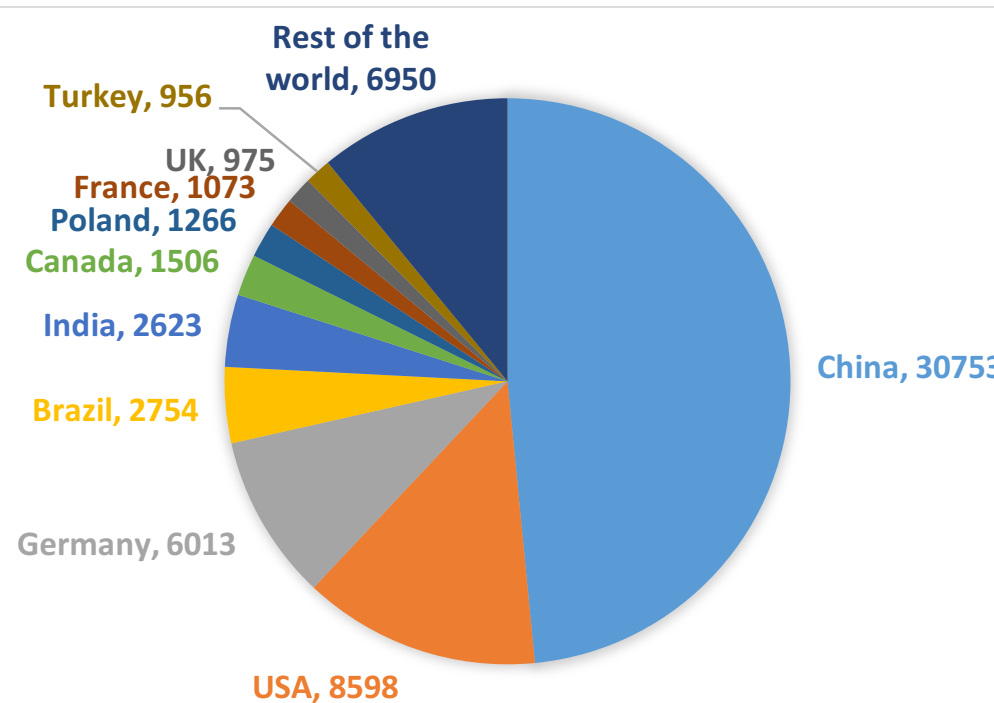

USA, 8598

Figure 1.1. New installed capacity in MW worldwide in 2015 [1] 


\subsection{Objective}

The overall objective of this thesis is to design retrofit winglets for the NREL 5MW reference wind turbine as a means of improving power output. Keeping in mind the objectives and economics of the wind industry today, key constraints are applied to the design process: there should be no need to structurally reinforce the blade in order to employ the winglet; and the winglet should be economically feasible. This is done by designing a winglet where the aerodynamic and centrifugal loads balance themselves to within a threshold, thereby minimizing the need for structural reinforcement. Secondly, the retrofit winglet is designed to be light and cheap, ensuring economic feasibility. As with any design process, the right tools are a necessity to arrive at an optimum design. Apt aerodynamic and economic tools are developed to aid with the design process and determine feasibility. An overview of current aerodynamic and economic models is presented in the following sections. The models employed in this study are presented in detail in subsequent chapters.

\subsection{Wind Turbine Aerodynamic Modelling}

Over the years, several models have been adopted and used for wind turbine aerodynamics. A brief overview of the models used are presented here:

\subsubsection{Rankine-Froude Actuator Disk Theory (1-D Momentum Theory)}

A simple and preliminary model used for wind turbine aerodynamics is the RankineFroude Actuator Disk Theory [2], also termed the 1-D Momentum Theory for wind turbines. In this model, the rotor is replaced by an actuator disc with an infinite number of blades. The disc is considered ideal and frictionless, producing no rotation in the flow [3]. Another key assumption is that of uniform velocity flow at the actuator disk. Wind approaches the rotor at a certain velocity and total pressure. The actuator disc can be considered as a drag device that 
slows down oncoming wind, extracting energy by reducing velocity and expanding the streamtube, with a subsequent drop in pressure at the rotor.

The 1-D Momentum Theory allows estimating energy extracted by a rotor. However, certain assumptions such as a wake with no rotation neglect the kinetic energy wasted in a rotating wake. Hence, it is essential to consider the rotation of the wake. Building on work done first by Joukowsky, and later Glauert, Wilson and Lissaman derived angular momentum equations of wake rotation as applied to wind turbines [4]. The 1-D Momentum Theory also fails to consider the impact of geometry of the rotor: solidity ratio, airfoils used, twist distribution and angles of attack at the blade.

\subsubsection{Classic Blade Element Momentum Method (Glauert Momentum Vortex Theory)}

The Classic Blade Element Momentum (BEM) Method developed by Glauert, also termed the Glauert Momentum Vortex Theory, has found extensive use in modelling wind turbine aerodynamics. The BEM method is an extension of the simpler one-dimensional Rankine-Froude Actuator Disc Theory. It uses the actuator disc model to balance momentum across an annular stream tube. The rotor is replaced by a uniformly loaded actuator disc, discretized into annular elements, with uniform inflow, followed by determining forces generated by the airfoil lift and drag coefficients. Angular momentum theorem is applied to approximate for wake rotation. The BEM method relies on the hypothesis that a section of a finite wing behaves as a section of an infinite wing at an angle of attack equal to the effective angle of attack [5].

In order to use the BEM method, a few key assumptions must be made. The BEM method assumes each annular element exerts constant force on the flow. It also assumes that flow is not radially dependent, that is, small annular sections can be analyzed independent of other sections. In reality, this is only true for a rotor with an infinite number of blades [3]. 
Approximate solutions, such as those derived by Prandtl or Goldstein, allow an aerodynamicist to correct for this simplification.

The BEM method has found favor in wind turbine design and analysis due to its ease of implementation and the fact that it is computationally fast. However, it remains that the BEM method can only be applied over a certain range of flow conditions. In addition, several correction factors (such as Prandtl's Tip Loss Factor to correct for a finite number of blades) need to be applied to allow a more realistic flow model. Application of several correction factors leads to uncertainties in the model, and in cases of large wake distortion (such as at high tip speed ratios), they are often incorrect [5]. For a thorough and extensive discussion on the 1-D Momentum theory and the BEM method, the reader is referred to texts by Eggleston and Stoddard [2], and Hansen [3].

While the BEM method is extremely quick and provides good results, it does not effectively model the flow at the tips of turbine blades, thereby rendering it ineffective to study the effects of winglets on wind turbines. The BEM method would have been inadequate for the purpose of this study, hence another effective aerodynamic model had to be considered. Vortex theory instead provides a powerful alternative to study such effects. A vortex lattice method with a prescribed wake, implemented in MATLAB, is used to study and gauge the effect of winglets on wind turbines. This model is further discussed in Chapter 2.

\subsection{Winglets for Wind Turbines - Prior Studies}

The idea of using blade tip devices on winglets is one that has been periodically explored in the past few decades. The earliest studies incorporating blade tip devices on wind turbines were done by Gyatt and Lissamann [6]. Drawing from advanced tip shapes that were being applied to fixed wing aircraft to reduce induced drag, the authors tested four tip designs on a 25kW Carter Wind Turbine in San Gorgonio Pass, California. The results were compared 
to analytical results obtained using the Wilson/Lissamann PROP code. Interestingly, while an increase in power produced was predicted, the authors' experimental data showed that using tip devices did not offer meaningful performance improvements. However, the authors believed that the reasons for this could be attributed to limited modeling tools available at that point in time. Primary among them would be the non-availability of effective analytical techniques to predict the effect of tip modifications, rising from a crude vortex lattice or the inaccurate implementation of viscous effects and a wake model.

Further studies were carried out in the subsequent decades. Van Bussel [7] developed a simple momentum theory for blade winglet configurations. Imamura et al. [8] analyzed the effects of winglets on wind turbines using a free-wake vortex lattice method. The study contrasted the effects of a simple span extension to winglets with varying cant angles, while taking note of the added blade root bending moment in both cases. It was shown that a winglet provides a similar increase in power as a span extension, but with a smaller increment in root bending moment. Guanna and Johansen [9] developed a free wake lifting line model to compute the effects of winglets, determining that downwind winglets on a wind turbine would be most efficient. The results from the free wake lifting line method were validated by comparing with CFD results obtained using EllipSys3D. The same study also employed a vortex cylinder analogy to show that winglets work by reducing tip effects. Johansen and Sørensen [10] did further studies on increasing power coefficient with the help of winglets using CFD. The authors tested five different winglet designs and pointed out that adding winglets definitely changes the downwash distribution, leading to an increase in the power produced. However, this study did not include a load analysis or structural model.

At this juncture, it is worth noting the primary differences between prior research and the work carried out in this thesis. Most studies focus on winglets as a device that would be incorporated into the blade at the time of manufacture. In exploring the retrofit aspect of 
winglets, this study takes into account the vast numbers of wind turbines currently in operation that could see a power improvement when utilizing winglets. In addition, retrofitting winglets does not lead to logistical challenges in transportation or installation. Secondly, unlike prior studies, a primary constraint set for the retrofit winglets designed in this thesis is that they must not cause a significant increase in root bending moments. This aspect is extremely significant as it ties into the idea of developing an economical winglet. A winglet where the generated winglet normal aerodynamic and centrifugal loads are not balanced will cause an increase in blade root bending moment. An increase in blade root bending moment would require the blade to be structurally reinforced, an expensive proposition that might negate any economic benefit derived from retrofitting a wind turbine with winglets in the first place.

\subsection{Economic Analysis}

As with any industry, economics is a parameter of extreme importance in the wind industry. Given how capital intensive the design, construction, testing and operation of a wind farm is, it is essential that studies and research projects factor in an economic analysis to determine feasibility of a project. In addition, the wind industry also faces stiff competition from the coal and natural gas industry, given the dirt cheap cost of energy using those sources. For the purchase of an individual wind turbine, Stoddard and Eggleston [2] provide a six-step process to evaluate the economy of the purchase. Reproduced below, with permission, is their process:

1. Estimating the output-power characteristic of the machine to be used versus wind speed.

2. Estimating the wind spectrum at the proposed site at hub level.

3. Estimating all costs associated with the purchase, installation and operation of the machine. 
4. Determining the worth of the utilized and "exported" electrical power produced.

5. Evaluating financial implications, including all applicable Federal and state tax credits, depreciation, costs of borrowing capital, and the effect of Federal and state income taxes.

6. Applying basic principles of engineering economy to evaluate the economic performance of the investment.

As a measure of economic performance, Levelized Cost of Energy (LCOE) is often used in the wind industry. The LCOE is a $\$ / \mathrm{KWh}$ value. It is the price of electricity that is necessary for a project for revenues to equal cost, and allow a return on capital investment [11]. A price above this yields a greater return on capital, while lower than that may lead to either a loss or a low return on capital. A complete economic analysis of an entire wind turbine is beyond the scope of this thesis. Instead, an economic analysis for retrofit winglets using LCOE is performed. This analysis is presented in Chapter 3. 


\section{CHAPTER 2}

\section{VORTEX LATTICE METHOD - THEORY AND APPLICATION}

\subsection{Introduction}

Understanding the flow around a wind turbine and gauging the effects of a winglet designed for the blade tip calls for a sound mathematical model predicting the aerodynamic forces and moments on a rotor. A vortex lattice method with a prescribed wake is a timeeffective and acceptably accurate method of modeling flow around a wind turbine. The theory and application of the Vortex Lattice Method presented in this chapter is based on the threedimensional numerical solutions explained in Katz and Plotkin [12].

Numerical methods, such as vortex lattice, lifting line and lifting surface methods, come under the category of potential flow theory or vortex theory. The underlying assumptions that govern potential flow theory is that flow is incompressible $(\bar{\nabla} \cdot \bar{V}=0)$, inviscid and irrotational $(\bar{\nabla} \times \bar{V}=0)$. For these assumptions, we can define a velocity potential $(\Phi)$, such that the velocity at each point is given by its gradient:

$$
\bar{V}=\nabla \Phi
$$

Substituting equation (2.1) into the continuity equation leads to Laplace's equation, a linear differential equation for the velocity potential:

$$
\nabla^{2} \Phi=0
$$

Thus, it is seen that for irrotational, inviscid and incompressible flow, the solution of Laplace's equation allows one to obtain the velocity field. In order to obtain a unique solution, boundary conditions and an elementary singularity solution must be specified. 


\subsection{Helmholtz's Theorems}

German scientist Hermann von Helmholtz developed three vortex theorems, which are summarized by Katz and Plotkin [12] as follows:

1. The strength of a vortex filament is constant along its length.

2. A vortex filament cannot start or end in a fluid (it must form a closed path or extend to infinity).

3. The fluid that forms a vortex tube continues to form a vortex tube and the strength of the vortex tube remains constant as the tube moves about (vortex elements will remain vortex elements with time).

This implies that vorticity is only generated at solid boundaries, and they can be considered a surface of vorticity. Hence, we can replace a solid surface in contact with a fluid by a surface of vorticity [5]. This allows us to use the vortex line as our singularity element and solve Laplace's equation. Thus, the wing and wake can be replaced by vortex ring elements, consisting of vortex filaments.

\subsection{The Biot-Savart Law}

The velocity induced by vortex filament is given by the Biot-Savart Law. For ease of numerical computations, Katz and Plotkin represent the Biot-Savart law as:

$$
\bar{v}_{i n d}=\frac{\Gamma}{4 \pi} \frac{\bar{r}_{1} \times \bar{r}_{2}}{\left|\bar{r}_{1} \times \bar{r}_{2}\right|^{2}} \bar{r}_{0}\left(\frac{\bar{r}_{1}}{r_{1}}-\frac{\bar{r}_{2}}{r_{2}}\right)
$$

Here, $\Gamma$ depicts the strength of the vortex element, $\bar{r}_{1}$ and $\bar{r}_{2}$ are the vectors from an arbitrary point $P$ to the start and end points of the vortex filament respectively, $\bar{r}_{0}$ is defined as:

$$
\bar{r}_{0}=\bar{r}_{2}-\bar{r}_{1}
$$

The Biot-Savart law is singular when the point of evaluation $P$ is located on the vortex filament. 
Phillips and Snyder [13] note that the formulation of the Biot-Savart law shown above is indeterminate whenever $\bar{r}_{1}$ and $\bar{r}_{2}$ are collinear, even if the points lie outside the vortex segment. An adaptation of the Biot-Savart law they suggest is:

$$
\bar{v}_{i n d}=\frac{\Gamma}{4 \pi} \frac{\left(\bar{r}_{1} \times \bar{r}_{2}\right)\left(r_{1}+r_{2}\right)}{r_{1} r_{2}\left(r_{1} r_{2}+\bar{r}_{1} \cdot \bar{r}_{2}\right)}
$$

The definitions of $\bar{r}_{2}, \bar{r}_{1}$ are as described previously. In addition, if the arbitrary evaluation point $P$ is very close to the vortex filament, the formulation yields unrealistically large induced velocities. In order to rectify this, it is recommended to use a cut-off radius. Thus, the formulation of the Biot-Savart law can be rewritten to include a cut-off radius $\delta$ :

$$
\bar{v}_{\text {ind }}=\frac{\Gamma}{4 \pi} \frac{\left(\overline{r_{1}} \times \bar{r}_{2}\right)\left(r_{1}+r_{2}\right)}{r_{1} r_{2}\left(r_{1} r_{2}+\bar{r}_{1} \cdot \bar{r}_{2}\right)+\left(\delta r_{0}\right)^{2}}
$$

With this notation of the Biot-Savart law and representing the blade surface as a surface of vorticity, it is possible to calculate rotor induced velocities at the rotor plane.

\subsection{Application}

In order to implement the Vortex Lattice Method, a grid must be generated. This is done by discretizing the blade camber surface into chordwise and spanwise panels. The singularity elements used are vortex rings. Each blade panel is overlaid with a vortex ring of strength $\Gamma$, thus representing it as a surface of vorticity. Here, positive circulation is determined using the Right Hand Rule. In addition, to satisfy the two-dimensional Kutta condition, the leading segment of each vortex ring is placed at the quarter-chord line of each panel [12]. Counters are assigned in the spanwise and chordwise directions, so the strength of each vortex panel is represented as $\Gamma_{\mathrm{ij}}$, where $i$ denotes the spanwise counter, while $j$ denotes the chordwise counter. Given that the circulation gradient can be quite large close to the tip and root of the rotor blade, it is recommended that the concentration of grid panels be increased in these areas. Indeed, van Garrel [14] recommends using cosine grid spacing for the blade for this reason. 
Similar to the blade, the wake and wake panels must also be generated. Vortex lattice methods with a free wake work by determining the exact path of trailing vortices iteratively [2]. While more accurate, these methods are complex and computationally more demanding, and also include the possibility of leading to diverging solutions. For the purpose of this study, a vortex lattice method with a prescribed (rigid) wake provides sufficiently accurate results, and hence will be used. For the initial wake geometry, the wake is described as a helix, given by the equations [15]:

$$
\begin{gathered}
x=V_{\infty} t \\
y=r_{i} \sin \left(\Omega t+\theta_{t}\right) \\
z=r_{i} \cos \left(\Omega t+\theta_{t}\right)
\end{gathered}
$$

Here, $V_{\infty}$ denotes freestream velocity, $t$ is time, $r_{i}$ is blade section radius, $\Omega$ is blade rotational velocity in radian/s and $\theta_{t}$ is blade section twist. Recalling that inviscid, incompressible and irrotational flows are underlying assumptions of the model, the wake vortices can be expected to extend up to infinity. Modeling the wake to extend to infinity is both unrealistic and inefficient. The velocity induced by a wake panel on the first blade panel five diameters downstream is of the order of $10^{-6} \mathrm{~m} / \mathrm{s}$. As this is close to negligible, it has been decided to model the wake to a distance approximately equal to five diameters downstream of the turbine. Figure 2.1 shows the blade surface panel overlaid with vortex rings. Also depicted are control points and unit normal vectors.

Having set up the blade and wake panels, the coordinates of the collocation (or control) points must be calculated. Circulation (bound vortex strength) and velocities induced by the trailing wake vortices are calculated at this point. These collocation points are located at the mid-point of each vortex ring (which is the three-quarter chord point of each blade panel). At this point, the normal vector at each control point is also defined. Figure 2.1 depicts the blade 
camber surface. For the sake of clarity, only a small segment of it and the generated wake discretized into panels.

The selected vortex ring singularities are based on the vortex line solution of the incompressible continuity equation [12]. In order to obtain a solution, the flow tangency boundary condition must be satisfied, that is, there should be zero normal flow across the boundary. In terms of velocity potential this can be written as:

$$
\nabla\left(\Phi+\Phi_{\infty}\right) \cdot \bar{n}=0
$$

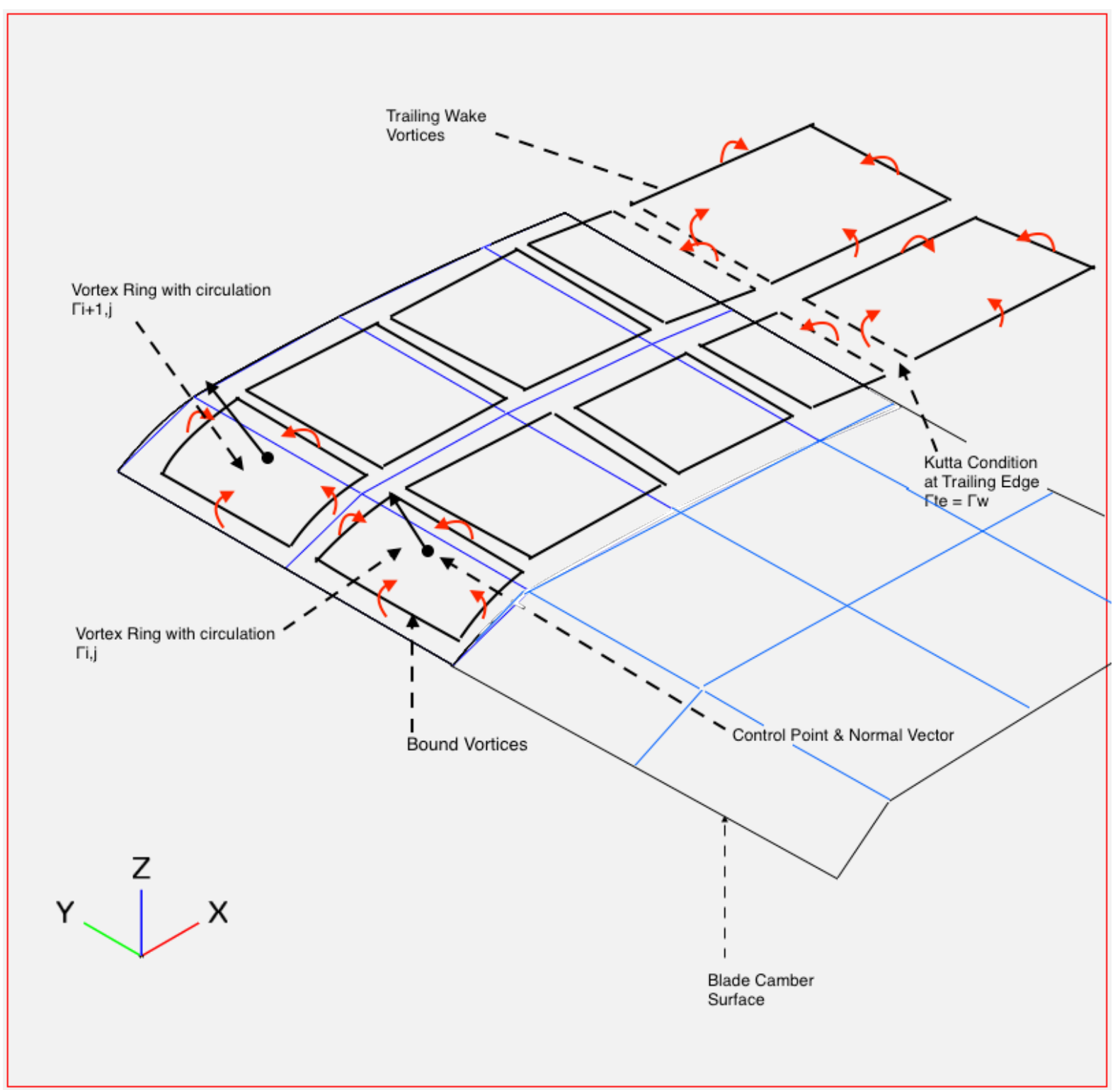

Figure 2.1. Blade camber surface overlaid with vortex rings. Also shown are the calculated control points and unit normal vectors 
That is, the sum of the normal component of the freestream and perturbation velocity potential must be zero. Rewriting in terms of velocities,

$$
\left(\bar{v}_{\infty}+\bar{v}_{\text {ind.,bound }}+\bar{v}_{\text {ind,wake }}+\bar{v}_{\text {rot }}\right) \cdot \bar{n}=0
$$

Here, $\bar{v}_{\infty}$ is the freestream inflow velocity, $\bar{v}_{\text {ind.,bound }}$ is the velocity induced by the vortex segments of the bound vortices, $\bar{v}_{\text {ind,wake }}$ is the velocity induced by the vortex segments of the trailing wake vortices and $\bar{v}_{\text {rot }}$ is the rotational velocity component $\left(\bar{v}_{\text {rot }}=\bar{\Omega} \times \bar{r}\right)$. The induced velocities, both due to the blade bound vortices and the trailing wake vortices, are calculated using the Biot-Savart Law. In order to solve for the circulation distribution across the blade, it is necessary to initialize a solution with some value of $\Gamma$ (circulation). This is done by initializing a solution for equation (2.10) with $\Gamma=1$.

At this point, it is possible to shift the normal components of the known velocity components to the right hand side of equation (2.10). Thus, applying the zero normal flow boundary condition at each colocation point, a system of equations can be constructed as shown below:

$$
\begin{gathered}
a_{11} \Gamma_{1}+a_{12} \Gamma_{2}+\cdots a_{1 N} \Gamma_{N}=-\left(\bar{v}_{\infty}+\bar{\Omega} \times \bar{r}\right) \cdot \bar{n}_{1} \\
a_{21} \Gamma_{1}+a_{22} \Gamma_{2}+\cdots a_{2 N} \Gamma_{N}=-\left(\bar{v}_{\infty}+\bar{\Omega} \times \bar{r}\right) \cdot \bar{n}_{2} \\
\cdots \cdots \cdots \cdots \cdots \\
a_{N 1} \Gamma_{1}+a_{N 2} \Gamma_{2}+\cdots a_{N N} \Gamma_{N}=-\left(\bar{v}_{\infty}+\bar{\Omega} \times \bar{r}\right) \cdot \bar{n}_{N}
\end{gathered}
$$

Here, $N$ denotes the total number of blade collocation points (for all three blades), $a_{\mathrm{ij}}$ denotes the influence coefficient of a certain collocation point, calculated as the sum of the normal bound and trailing velocities induced by a vortex ring of strength one $(\Gamma=1)$ at the concerned collocation point. Thus, $a_{\mathrm{ij}}$ is the influence of the $j^{\text {th }}$ vortex ring on the $i^{\text {th }}$ blade collocation point, written as:

$$
a_{i j}=\left(\bar{v}_{i, j_{\text {ind bound }}}+\bar{v}_{i, j_{\text {ind trailing }}}\right) \cdot \bar{n}_{i}
$$


Rewriting the system of equations (2.11) as matrices, we have:

$$
\left(\begin{array}{ccc}
a_{11} & \cdots & a_{1 N} \\
\vdots & \ddots & \vdots \\
a_{N 1} & \cdots & a_{N N}
\end{array}\right)\left(\begin{array}{c}
\Gamma_{1} \\
\vdots \\
\Gamma_{N}
\end{array}\right)=-\left(\begin{array}{c}
\left(\bar{v}_{\infty}+\bar{\Omega} \times \bar{r}\right) \cdot \bar{n}_{1} \\
\vdots \\
\left(\bar{v}_{\infty}+\bar{\Omega} \times \bar{r}\right) \cdot \bar{n}_{N}
\end{array}\right)
$$

In order to compute the circulation distribution, it is necessary to specify the Kutta condition $(\gamma=0)$ at the trailing edge of the blade. This is done by specifying that the strength of the trailing vortex rings must be equal to the blade vortex ring at the trailing edge, allowing the trailing vortex of the last panel to be cancelled out. Since the strength of the wake vortex panels do not change with time, they can be converted to trailing horseshoe vortices [5]. Thus, the effect of each trailing wake panel is added to the last chordwise panel of its respective spanwise segment. The circulation matrix can now be solved for the circulation distribution across the blade. The correct induced velocities can be determined using the computed circulation values.

Having calculated the induced velocities, it is possible to calculate effective angles of attack at each spanwise section. The geometric angles of attack at the blade sections are computed as:

$$
\alpha_{\text {geom }}=\tan ^{-1}\left(\frac{\bar{v}_{n}}{\bar{v}_{t}}\right)
$$

Here, $\bar{v}_{n}$ is the sum of the rotational and freestream velocity normal to the blade, while $\bar{v}_{t}$ is the sum of the rotational and freestream velocity tangent to the blade. As one may expect, velocities induced by the trailing wake leads to a reduction in the angle of attack. This angle of attack, termed the effective angle of attack, is calculated as:

$$
\alpha_{e f f}=\tan ^{-1}\left(\frac{\bar{v}_{t o t, n}}{\bar{v}_{t o t, t}}\right)
$$

Here, $\bar{v}_{t o t}$ is the total velocity, written as:

$$
\bar{v}_{t o t}=\bar{v}_{\infty}+\bar{v}_{i n d ., b o u n d}+\bar{v}_{i n d, w a k e}+\bar{\Omega} \times \bar{r}
$$


$\bar{v}_{t o t, n}$ and $\bar{v}_{t o t, t}$ are the total velocity components normal and tangential to the blade, respectively.

In an effort to quantify viscous effects, two-dimensional airfoil data is used to calculate lift and drag forces. With the effective angle of attack at each spanwise section having been calculated, it is possible to determine section lift and drag coefficients, and subsequently lift and drag forces, for airfoil sections across the blade span. These are decomposed into tangential and normal forces, and are used to compute the power generated by the wind turbine. Using the induced velocities, the wake geometry can be updated by [5]:

$$
\begin{gathered}
x=\bar{v}_{u p d} t \\
y=r_{i} \sin \left(\Omega_{u p d} t+\theta_{t}\right) \\
z=r_{i} \cos \left(\Omega_{u p d} t+\theta_{t}\right)
\end{gathered}
$$

Here, $\bar{v}_{\text {upd }}=\bar{v}_{\infty}+\bar{v}_{\text {ind,x }}, \Omega_{\text {upd }}=\Omega+\frac{v_{\text {ind,circ. }} .}{r_{i}}$. The wake is continually updated until the difference between successive computed power values is marginal. An updated wake

\subsection{Method}

The Vortex lattice method implemented in this thesis is written using MATLAB [16], with model and grid generation done using Vehicle Sketch Pad (OpenVSP) [17], an open source software released under the NASA Open Source Agreement.

\subsubsection{Geometry}

To demonstrate the effects of retrofit winglets, it is essential to have a baseline wind turbine to compare to, and design the winglets for. Several commercial designs currently in use were considered. However, much of the important design characteristics of such wind turbines remain proprietary. Instead, the NREL 5MW reference wind turbine [18] has been selected as the baseline wind turbine. The NREL 5MW reference wind turbine is a conceptual three-bladed upwind turbine that was primarily designed to support concept studies. It is heavily based on 
the Repower 5MW wind turbine; however, in cases where detailed information is not available, data from publicly available conceptual studies is used. The excellent and extensive information available, and the ease with which it could be obtained are key factors in selecting the NREL 5MW reference wind turbine as the baseline wind turbine for this study. Table 2 lists the specifications of the NREL 5MW reference wind turbine, as listed in Jonkman et al [18].

TABLE 2

SPECIFICATIONS OF THE NREL 5MW REFERENCE WIND TURBINE

\begin{tabular}{|c|c|c|c|}
\hline Radial Position (m) & Chord (m) & Twist ( $\left.{ }^{\circ}\right)$ & Airfoil \\
\hline 11.75 & 4.557 & 13.308 & DU40_A17 \\
\hline 15.85 & 4.652 & 11.480 & DU35_A17 \\
\hline 19.95 & 4.458 & 10.162 & DU35_A17 \\
\hline 24.05 & 4.249 & 9.011 & DU30_A17 \\
\hline 28.15 & 4.007 & 7.795 & DU25_A17 \\
\hline 32.20 & 3.748 & 6.544 & DU25_A17 \\
\hline 36.35 & 3.502 & 5.361 & DU21_A17 \\
\hline 40.45 & 3.256 & 4.188 & DU21_A17 \\
\hline 44.55 & 3.010 & 3.125 & NACA64_618 \\
\hline 48.65 & 2.764 & 2.319 & NACA64_618 \\
\hline 52.75 & 2.518 & 1.526 & NACA64_618 \\
\hline 56.16 & 2.313 & 0.863 & NACA64_618 \\
\hline 58.90 & 2.086 & 0.370 & NACA64_618 \\
\hline 61.63 & 1.419 & 0.106 & NACA64_618 \\
\hline
\end{tabular}


It was elected to use Vehicle Sketch Pad (OpenVSP) to model the geometry of the NREL $5 \mathrm{MW}$ reference wind turbine. OpenVSP is a parametric geometry modelling tool that allows users to swiftly model configurations and generate geometry that can be utilized by higherorder tools, such as the VLM developed for this thesis. Using the turbine structural and aerodynamic properties provided in Jonkman et al. [18], the NREL 5MW reference turbine was modeled in OpenVSP, with density of spanwise and chordwise panels specified. Subsequently, a plate geometry was generated and imported into MATLAB, to which blade camber was added to reproduce the camber line. A plot of the blade geometry is shown in Figure 2.2

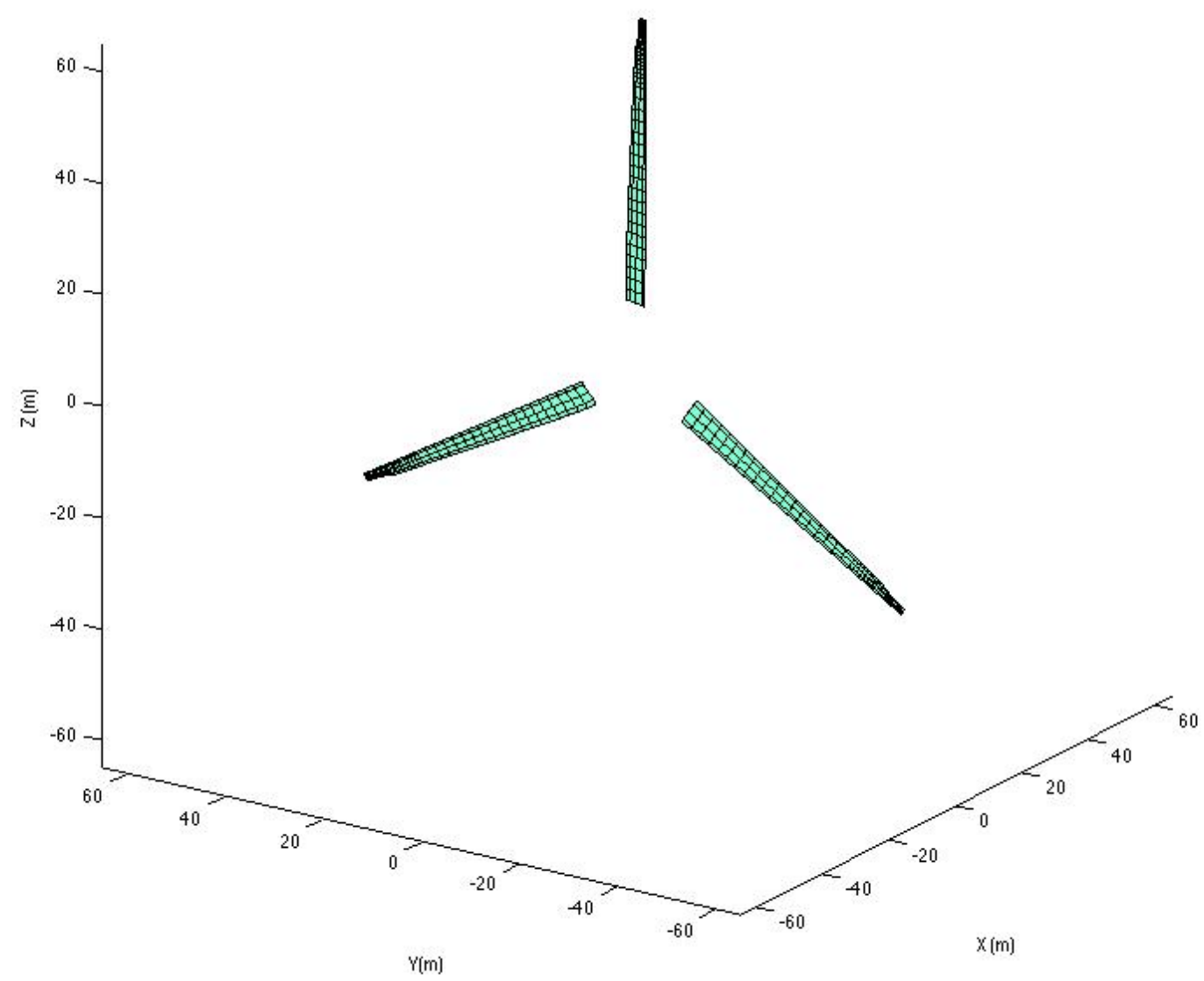

Figure 2.2. Discretized geometry of the NREL 5MW reference wind turbine with defined coordinate system. 
Figure 2.3 shows a magnified view of the blade camber surface. As can be seen in the figure, the number of chordwise panels used in this study is 4 , from leading edge to trailing edge. Additionally, the number of spanwise sections for the baseline wind turbine used are 43 .

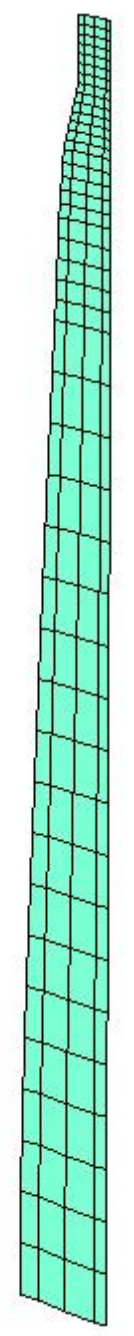

Figure 2.3. Magnified view of the spanwise and chordwise panels on one blade.

As described in the previous section, after importing the geometry into MATLAB, the prescribed wake is generated, collocation points computed and vortex rings overlaid on the blade and wake panels. Following this, circulation distributions, induced velocities and effective angles of attack are calculated to obtain power generated. Figure 2.4 shows the blade geometry and the prescribed wake generated for one blade in the implemented VLM. Validation and results are presented in the following section. 


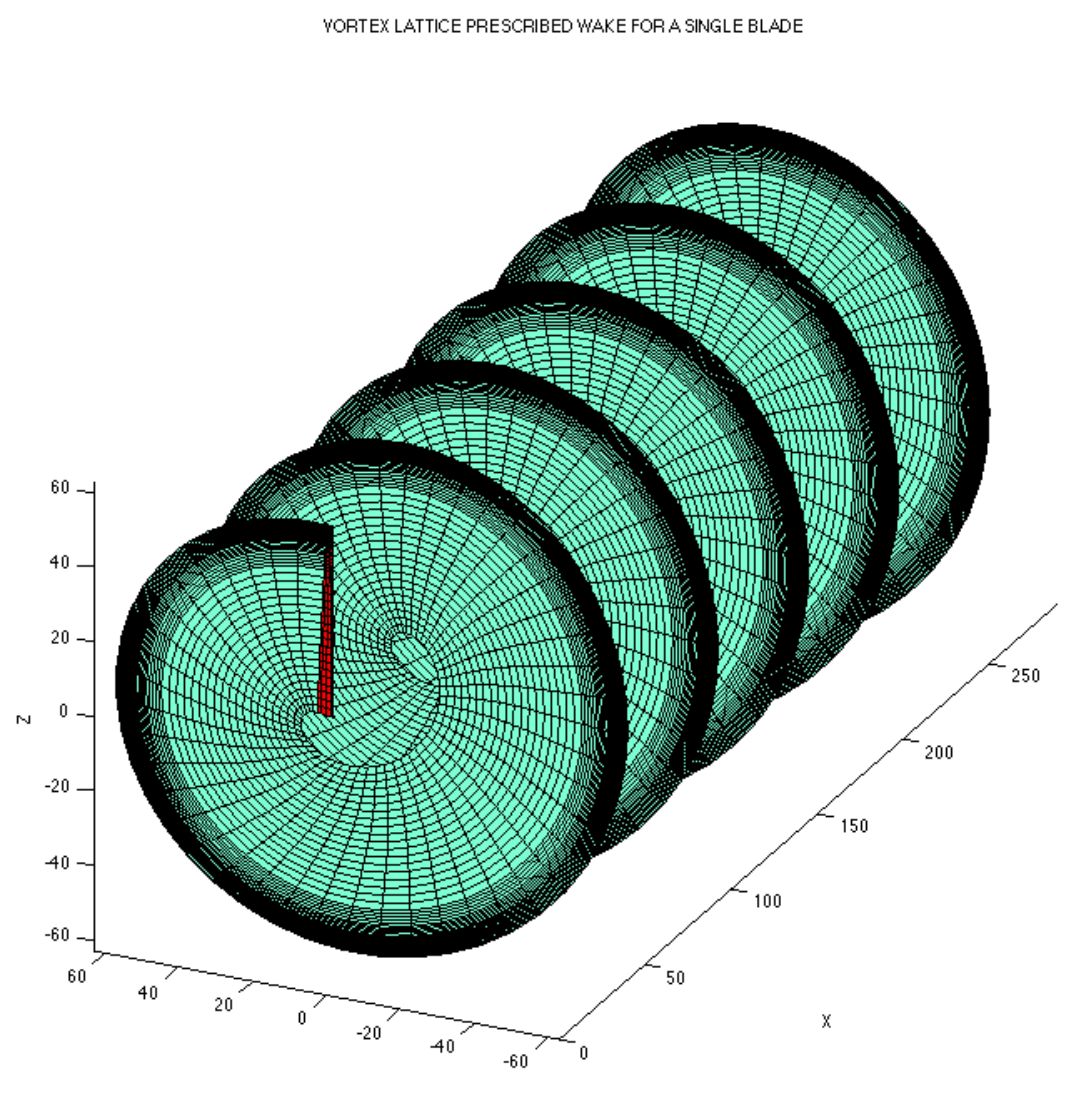

Figure 2.4. Vortex lattice prescribed wake for a single blade

\subsection{Results and Validation}

As with any computational tool, it is essential to be able to compare obtained results with those obtained by either experimental methods or results from validated software. In the absence of experimental data to compare to, the VLM implemented in this thesis is compared to results obtained using the lifting line module in QBlade [19], an open source simulation software for wind turbines developed at the Technical University of Berlin. QBlade has been extensively validated against experimental data and results from other codes. For detailed results on the validation of QBlade, the reader is referred to Pechlivanoglou et al [19]. In 
addition, the circulation distribution and angles of attack distribution are also compared with results obtained by Abedi [5].

Results are obtained for the NREL 5MW reference wind turbine at a wind speed of 8 $\mathrm{m} / \mathrm{s}$, and a tip speed ratio of 7.55. Jonkman et al. [18] suggest that these operating conditions lead to maximum $C_{p}$. These operating conditions are fed into QBlade to obtain results, and are used as the freestream inflow velocity and rotational velocity respectively. The results are compared in Table 3.

TABLE 3

COMPARISON OF RESULTS USING DIFFERENT METHODS

\begin{tabular}{|c|c|c|}
\hline Model & Power Generated $(\mathrm{kW})$ & Coefficient of Power $\left(\mathrm{C}_{\mathrm{p}}\right)$ \\
\hline QBlade Lifting Line Model & 2087 & 0.5340 \\
\hline Vortex Lattice Method & 2007 & 0.5134 \\
\hline NREL 5MW Reference [18] & 1884 & 0.4820 \\
\hline
\end{tabular}

The variation in the results may be attributed to two primary reasons. The first is that unlike the VLM implemented here, QBlade employs a free wake model. The second cause for variation may be attributed to the fact that QBlade uses a lifting line simulation, unlike the lifting surface simulation employed in this Vortex Lattice Method. Nevertheless, the results shown in Table 2 establish that the VLM implemented here provides results that can be used to quantify the benefit of a winglet.

In addition to comparisons of $C_{p}$, circulation and effective angle of attack values are also compared. These comparisons are made with Abedi's Licentiate thesis [5]. Abedi also uses the NREL 5MW reference wind turbine in his study. However, specific details on how the turbine was modeled are missing from the study, which is a cause for concern when making direct comparisons. Abedi's results are for the NREL 5MW reference wind turbine with 
operational conditions of $v_{\infty}=8 \mathrm{~m} / \mathrm{s}$ and $\Omega=1.0032 \mathrm{rad} / \mathrm{s}$. Accordingly, these conditions are used in the implemented vortex lattice method. Figure 2.5 depicts the effective angle of attack obtained with the VLM compared to those seen in Abedi [5]. Also seen is the geometric angle of attack distribution along the blade obtained with the VLM. In the implemented VLM code, to compute the induced angle of attack along a spanwise segment, the induced velocities of each panel in the chordwise direction is averaged, and this value is used to compute effective angle of attack. This averaging may explain the slight oscillations in angle of attack towards the outboard regions of the blade. Figure 2.6 shows the circulation distribution along the blade. Both results are quite close to results obtained by Abedi in his Licentiate thesis [5].

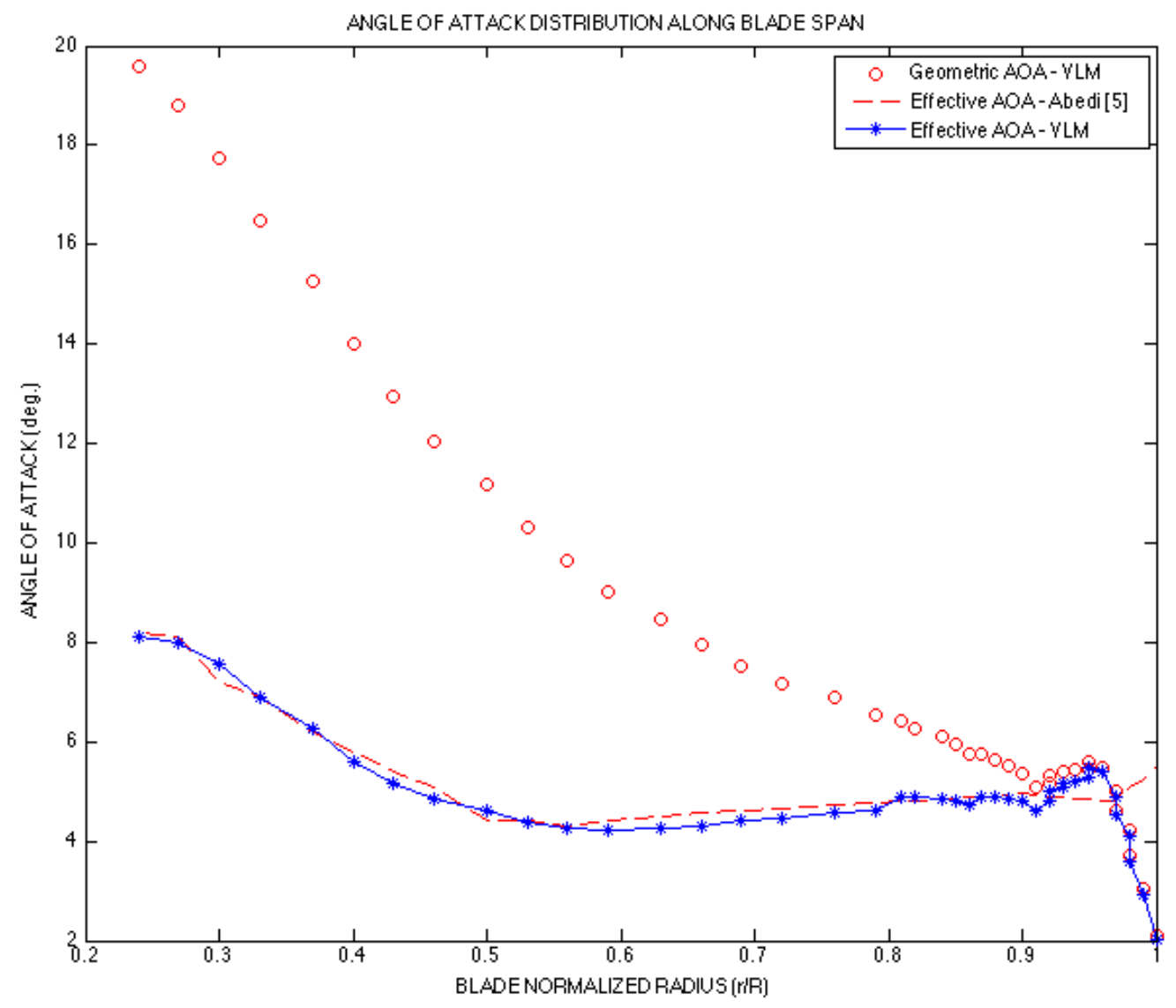

Figure 2.5. Geometric and effective angle of attack distributions along blade span 


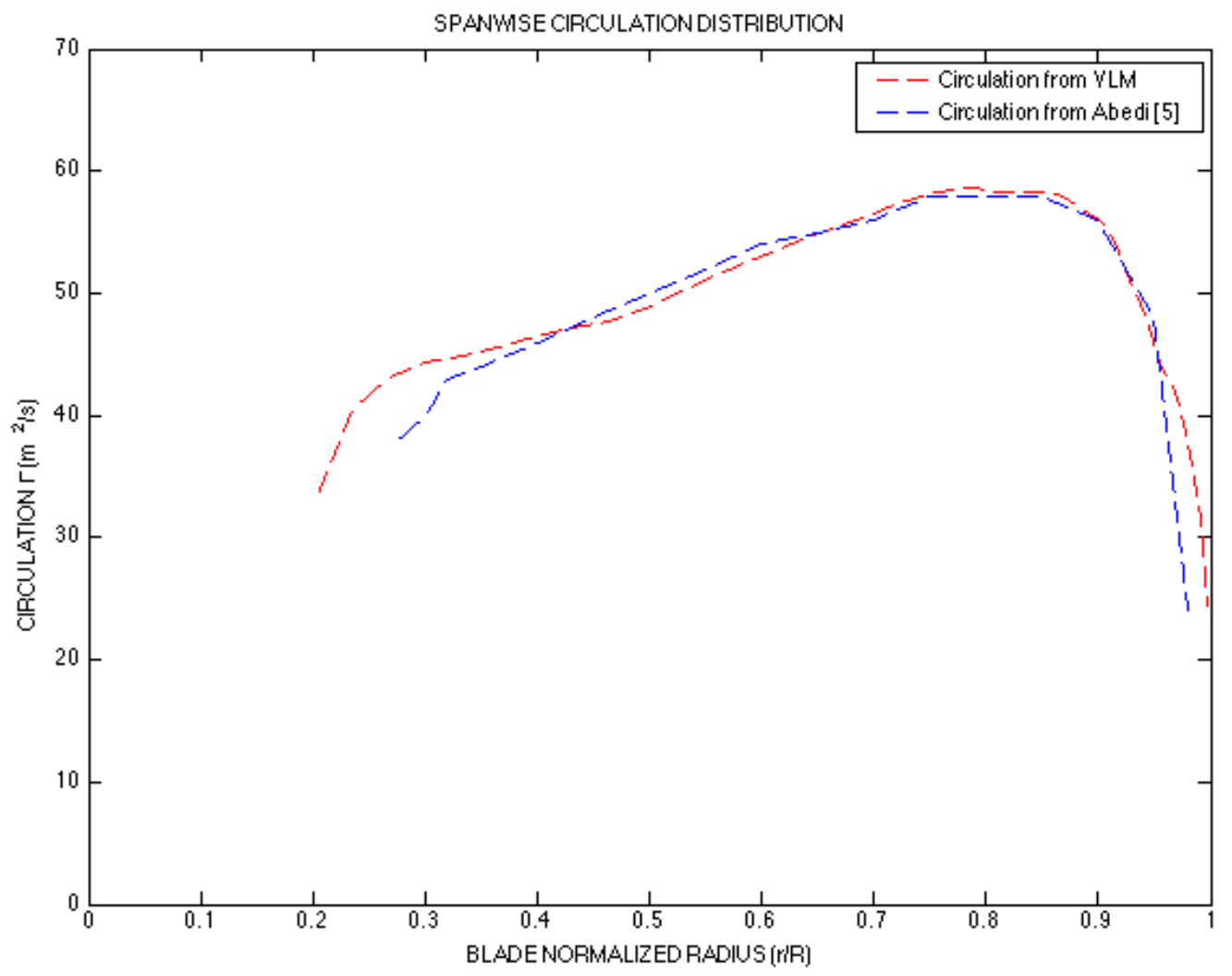

Figure 2.6. Circulation distribution along blade span

At this stage, it is essential to note that the objective of implementing a VLM in this thesis is not to be able to reproduce exactly the results produced by QBlade or seen in Abedi [5]. Rather, the aim of the author is to be equipped with a tool that models tip effects to some accuracy, and quantifies a change in power produced when using a winglet. The results discussed in this section show that the implemented VLM is more than capable of meeting these requirements. 


\section{CHAPTER 3}

\section{ECONOMIC MODEL}

\subsection{Introduction}

As outlined in Chapter 1, economics is a significant aspect of the wind industry. While wind continues to be a clean and economically viable source of energy, setting up a wind farm requires a large amount of initial capital [20], and can lead to narrow profit margins. History is littered with countless examples of innovations that, while useful, were far too expensive to apply practically or be financially viable. Being cognizant of this, this study strives to prove the financial viability of retrofit winglets for wind turbines. Indeed, for an industry that operates on slim margins, that new innovations must demonstrate their financial viability is an understood and expected outcome.

\subsection{Cost of Energy}

A widely accepted measure of economic return used in the wind industry is the Levelized Cost of Energy (LCOE). Cost of Energy is usually a $\$ / \mathrm{kWh}$ value that pegs a dollar value for every unit of energy generated. It is convenient to "levelize" this value, that is, convert the net expenditure and income into an equivalent yearly amount [2]. The LCOE model used in this thesis is one based on Fingersh et al's cost scaling model [20], described below:

$$
L C O E=\frac{I_{t}+M_{t}}{E_{t}}
$$

Here, $I_{t}$ is the Initial Cost per year, $M_{t}$ the annual Operating Expense and $E_{t}$ is the Annual Energy Output (AEO).

\subsubsection{Initial Cost}

The Initial Cost consists of two components. The first is the initial capital cost $\left(I_{c}\right)$, that covers the cost of fabrication and setting up of the wind turbine, broken down into an annual 
value for the life of the wind turbine. The second component is the Fixed Charge Rate (FCR). The FCR includes the cost of raising capital, interest on debt and equity, taxes, depreciation and insurance [20]. The Initial Cost per year of the life of the wind turbine is calculated as:

$$
I_{t}=\frac{I_{c} \times F C R}{n}
$$

Here, $n$ is the life of the turbine. Most wind turbines today are designed with an average life span of twenty years [2]. Accordingly, that is considered as the life span in this cost model. In accordance with the findings in Fingersh et al [20], an FCR of $11.58 \%$ is employed in this study.

\subsubsection{Annual Operating Expense}

Simply described, the annual operating expense is the cost of operating and maintaining the wind turbine. It includes the Operation and Maintenance (O\&M) Costs, Land Lease Costs (LLC) and the Levelized Replacement Costs (LRC). The O\&M cost is described as the cost per year required to operate and maintain the wind turbine. It includes the cost of labor and parts for scheduled and unscheduled maintenance, supplies and administration. LLC is the annual cost to lease the plot of land or ocean bottom on which the wind turbine is situated. The LRC is a fund to cover the overhaul or replacement of components of the wind turbine over its lifespan, levelized to an annual value [20].

\subsubsection{Annual Energy Output}

The Annual Energy Output (AEO) is a kWh value of the net energy produced by the wind turbine. It is calculated by taking into account the wind speed frequency distribution at a selected site, the power curve of the wind turbine and rotor efficiency. For the purpose of this study, it is assumed that the baseline wind turbine is located in Wichita, Kansas. Jong and Thoman's report [21] is part of an excellent series of Wind Energy Reports (WERs) produced at Wichita State University in the 1970s, and documents wind speed data for Wichita measured at a height of 25 feet. The report provides Weibull wind speed probability distributions, with 
shape and scale factors. The power curve for the NREL 5MW is calculated using the approximate cubic power curve method described by Carillo, Montano, Cidras, J., and DiazDorado [21]. Rotor efficieny of $94.4 \%$ is used, as described in Jonkman et al [18].

\subsection{Notes on the Cost of Energy Model}

The definition of the NREL 5MW reference wind turbine in Jonkman et al [18], while extensive, does not provide an estimate of the costs required to fabricate the turbine, or the Cost of Energy (COE) produced. In order to demonstrate the financial viability of retrofit winglets, it is essential to arrive at a baseline cost of energy for the NREL 5MW Reference Wind Turbine. This is done using the cost scaling factors available in Fingersh et al [20]. Since the scaling factors provide values in 2002 dollars, the costs are scaled to equivalent 2016 dollars using data from the US Bureau of Labor Statistics [23].

At this juncture, it is essential to be acquainted with the fact that the objective of employing a cost model in this study is not to arrive at an authoritative cost estimate of the NREL 5MW Reference turbine. Rather, the aim of using scaling models to arrive at a cost estimate is to have a baseline cost for comparison. Since the baseline cost remains the same for all cases (with and without winglets), the cost of as well as any benefit or drawback of using retrofit winglets is aptly demonstrated. Indeed, the key parameter to focus on in this study would be the figure of merit $\left(\Delta \mathrm{C}_{\mathrm{p}} / \Delta \$\right)$ introduced in Chapter 4.

\subsection{Baseline Cost of Energy for the NREL 5MW Reference Wind Turbine}

As noted previously, a baseline LCOE is necessary to be able to show any advantages or disadvantages of using retrofit winglets. Subsequently, using the cost factors available in Fingersh et al [20], it is possible to arrive at a baseline cost, and subsequently LCOE, for the 
NREL 5MW reference wind turbine. For the purpose of this study, it has been opted to site the wind turbine on land, rather than offshore, thus on-shore scaling factors are employed.

\subsubsection{Initial and Operating Cost of the Baseline NREL 5MW Wind Turbine}

Components of the installed capital cost and operating expenses, calculated in 2002

dollars, are converted to 2016 dollars, and is presented in Table 3. Using the FCR and life span stated in section 3.2.1, it is possible to arrive at an initial cost per year of the lifespan of the wind turbine. This is included in Table 4. 
TABLE 4

INITIAL COSTS AND OPERATING EXPENSES FOR THE BASELINE NREL 5MW REFERENCE WIND TURBINE

\begin{tabular}{|c|c|c|}
\hline Component & 2002 Dollars & 2016 Dollars \\
\hline Blades & $\$ 644,508$ & $\$ 863,641$ \\
\hline Hub & $\$ 91,473$ & $\$ 122,574$ \\
\hline Pitch System & $\$ 183,552$ & $\$ 245,959$ \\
\hline Nose Cone & $\$ 10,085$ & $\$ 13,513$ \\
\hline Low Speed Shaft & $\$ 11,582$ & $\$ 15,519$ \\
\hline Bearing & $\$ 95,050$ & $\$ 127,366$ \\
\hline Gearbox & $\$ 636,163$ & $\$ 852,458$ \\
\hline Generator & $\$ 240,150$ & $\$ 321,801$ \\
\hline Variable Speed Electronics & $\$ 395,000$ & $\$ 529,300$ \\
\hline Yaw Drive and Bearing & $\$ 113,954$ & $\$ 152,698$ \\
\hline Mainframe & $\$ 58,231$ & $\$ 78,030$ \\
\hline Platforms and Railings & $\$ 23,672$ & $\$ 31,720$ \\
\hline Electrical Connections & $\$ 200,000$ & $\$ 268,000$ \\
\hline Hydraulic and Cooling System & $\$ 60,000$ & $\$ 80,400$ \\
\hline Brake/Coupling Cost & $\$ 9,920$ & $\$ 13,293$ \\
\hline Nacelle Cover & $\$ 61,535$ & $\$ 82,456$ \\
\hline $\begin{array}{l}\text { Control/Safety, Condition } \\
\text { Monitoring }\end{array}$ & $\$ 35,000$ & $\$ 46,900$ \\
\hline Tower & $\$ 456,153$ & $\$ 611,245$ \\
\hline Foundation & $\$ 83,985$ & $\$ 112,540$ \\
\hline Transportation & $\$ 1,312,250$ & $\$ 1,758,415$ \\
\hline Roads and Civil Work & $\$ 256,450$ & $\$ 343,643$ \\
\hline Assembly and Installation & $\$ 112,683$ & $\$ 150,995$ \\
\hline Electrical Interface & $\$ 432,250$ & $\$ 579,215$ \\
\hline Engineering Permits & $\$ 126,400$ & $\$ 169,376$ \\
\hline Installed Capital Cost $\left(\mathbf{I}_{\mathbf{C}}\right)$ & $\$ 5,650,042$ & $\$ 7,571,057$ \\
\hline Fixed Charge Rate (FCR) & \multicolumn{2}{|l|}{$11.58 \%$} \\
\hline Lifespan & \multicolumn{2}{|l|}{20 years } \\
\hline Initial Cost per year & $\$ 315,216$ & $\$ 422,389$ \\
\hline
\end{tabular}

Table 5 outlines the Annual Operating Expense for the NREL 5MW Reference Wind Turbine. 


\section{TABLE 5}

ANNUAL OPERATING EXPENSE FOR THE BASELINE NREL 5MW REFERENCE WIND TURBINE

\begin{tabular}{|l|l|l|}
\hline Component & $\mathbf{2 0 0 2}$ Dollars & $\mathbf{2 0 1 6}$ Dollars \\
\hline O\&M Costs & $\$ 152,445$ & $\$ 204,276$ \\
\hline Land \& Lease Cost & $\$ 23,520$ & $\$ 31,517$ \\
\hline Levelized Replacement Cost & $\$ 53,500$ & $\$ 71,690$ \\
\hline Annual Operating Expense & $\mathbf{\$ 2 2 9 , 4 6 5}$ & $\mathbf{\$ 3 0 7 , 4 8 3}$ \\
\hline
\end{tabular}

\subsubsection{Annual Energy Output of the Baseline NREL 5MW Wind Turbine}

To compute the AEO of the baseline wind turbine, the Weibull shape and scale factors for Wichita at a height of 25 feet available in Jong and Thoman [21] are scaled to a hub height of $90 \mathrm{~m}$ (296 feet). The variations of Weibull parameters with height are given in Frost et al [24]. The Weibull-fitted wind speed frequency distribution for Wichita at a hub height of 90 meters is shown in Figure 3.1.

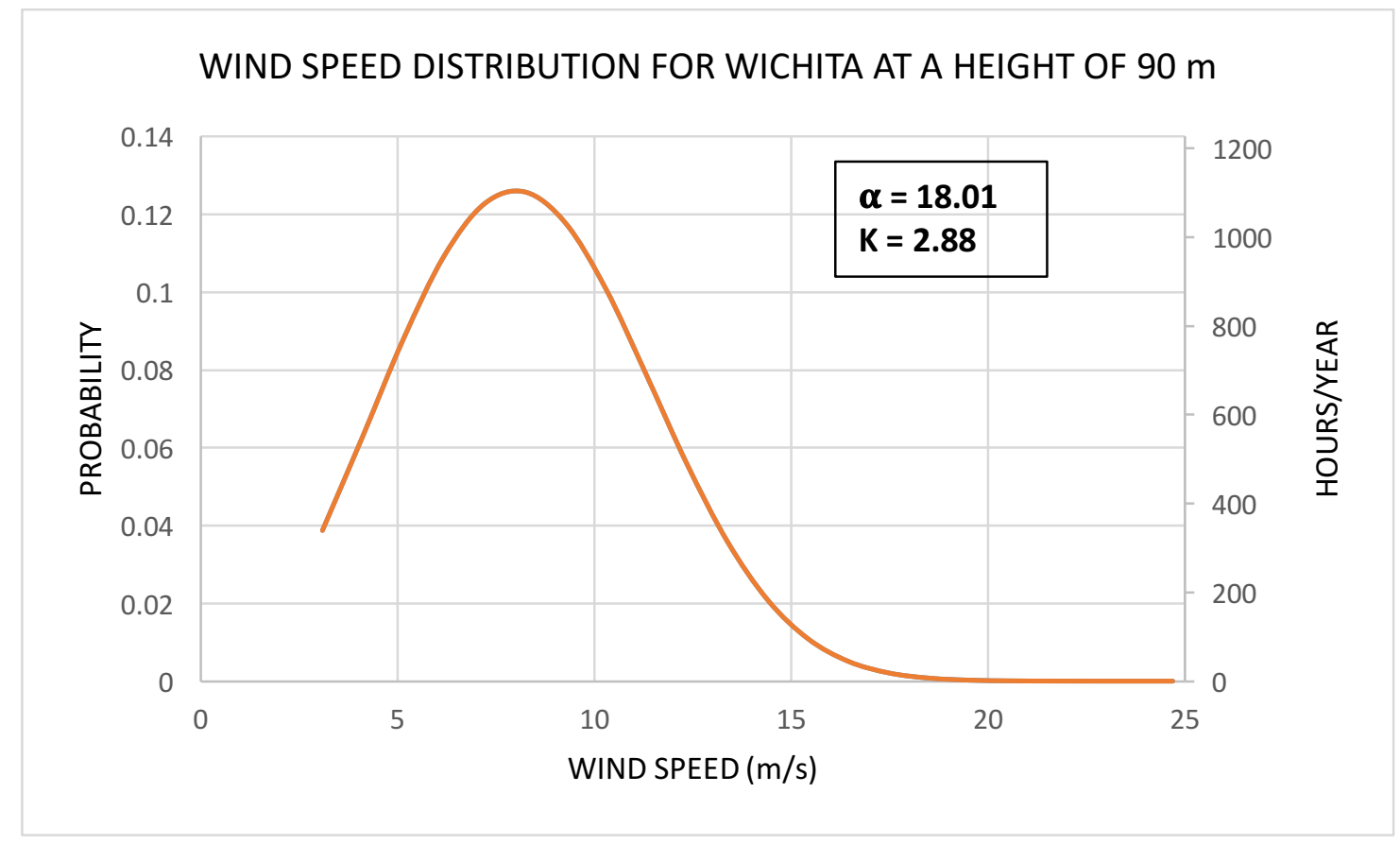

Figure 3.1 Weibull-fitted wind speed frequency distribution for Wichita

The power curve of the Baseline NREL 5MW wind turbine is computed using the approximate cubic power curve method shown in Carillo et al [22], with the computed 
maximum power coefficient of 0.5134 (from Table 3 ) being used. Figure 3.2 depicts the power curve for the baseline wind turbine. The approximate cubic power curve method requires that 'effective' maximum coefficient of power be used. Subsequently, a generator efficiency of $94.4 \%$ is used, as stated in [18].

Using the computed power curve and wind speed frequency distribution, the Annual Energy Output $\left(E_{t}\right)$ of the baseline wind turbine can be computed as:

$$
E_{t}=8760 \text { hours } \times \int_{V_{\text {Cut-in }}}^{V_{\text {Cut-out }}} P(v) f(v) d v
$$

Here, $P(v)$ is the power generated as a function of wind speed (obtained from the power curve), $f(v)$ is the probability density function as a function of wind speed. The obtained AEO value is generally expressed in units of Kilowatt Hours (kWh).

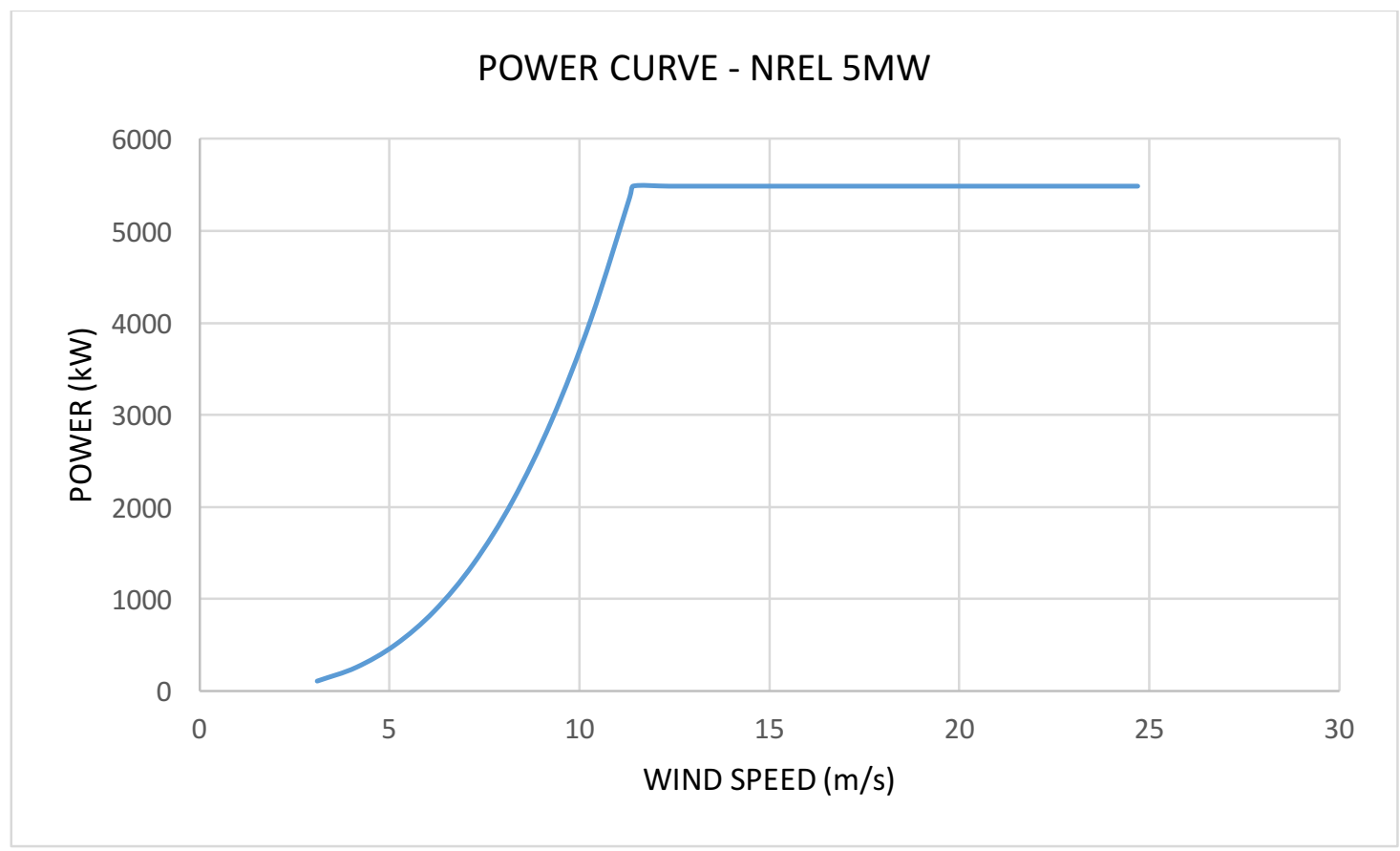

Figure 3.2 Power curve for the baseline NREL 5MW wind turbine

A summation of the Initial Cost, Annual Operating Expenses and Annual Energy Output of the baseline NREL 5MW is presented in Table 6. The LCOE for the baseline wind turbine is also shown. 
TABLE 6

LEVELIZED COST OF ENERGY FOR THE BASELINE NREL 5MW WIND

TURBINE (in 2016 dollars)

\begin{tabular}{|c|c|}
\hline Initial Cost per year $\left(\mathrm{I}_{\mathrm{c}}\right)$ & $\$ 422,389$ \\
\hline Annual Operating Expenses $\left(\mathrm{M}_{\mathrm{t}}\right)$ & $\$ 307,483$ \\
\hline Annual Energy Output $\left(\mathrm{E}_{\mathrm{t}}\right)$ & $21,777,132 \mathrm{kWh}$ \\
\hline Levelized Cost of Energy $(\mathbf{L C O E})$ & $\mathbf{\$ 0 . 0 3 3 5 / \mathbf { k W h }}$ \\
\hline
\end{tabular}

Having established a baseline cost of energy, it is possible to determine aerodynamic and monetary benefits that retrofit winglets may offer. The winglets designed are discussed in Chapter 4. 


\section{CHAPTER 4}

\section{RETROFIT WINGLET DESIGN}

\subsection{Design Philosophy}

The key differentiator between this study and others that design winglets for wind turbines has been the design philosophy: designing a light winglet at minimum cost that, while providing a measurable improvement in Coefficient of Power $\left(C_{p}\right)$, balances the centrifugal force, weight and normal component of the aerodynamic force. Balancing forces minimizes increase in blade root bending moment, negating the need for an exceptionally strong winglet and allowing it to be light. Savings in weight are strongly linked to cost, so a lighter winglet implies a cheaper, more cost effective one. It is thus understood that a winglet that provides maximum increase in $C_{p}$ may not necessarily be the best design, for it may be too heavy or too expensive. Accordingly, a Figure of Merit (FOM) has been developed that accurately singles out an optimum design.

A free-body diagram of the winglet at $0^{\circ}$ azimuth is shown in Figure 4.1 Throughout the blade's revolution, the centrifugal force and the normal vector of the aerodynamic force act in opposite directions. The weight vector, however, always acts downwards. Thus, it is essential to try and maintain weight to a reasonable minimum.

Subsequently, three designs are presented in this study. With the first iteration, Design A, it is sought to arrive at the lightest and cheapest configuration that can be safely used. Design B is exactly similar to Design A, but with added aluminum connectors to buttress the joint with the main wind turbine blade. Design $\mathrm{C}$ acts as a control design, that is, it is constructed in exactly the same manner as the main blade. Indeed, Design $\mathrm{C}$ can be termed as a retrofit winglet for wind turbines that employs 'traditional construction' techniques. Designs A and B incorporate a foam core, balsa spar and fiberglass skin. Care is taken to ensure that the foam 
core is one that does not absorb or retain water in stormy conditions. As Design B calls for aluminum connector rods, an adapter to easily attach it to the end of the turbine blade has been designed.

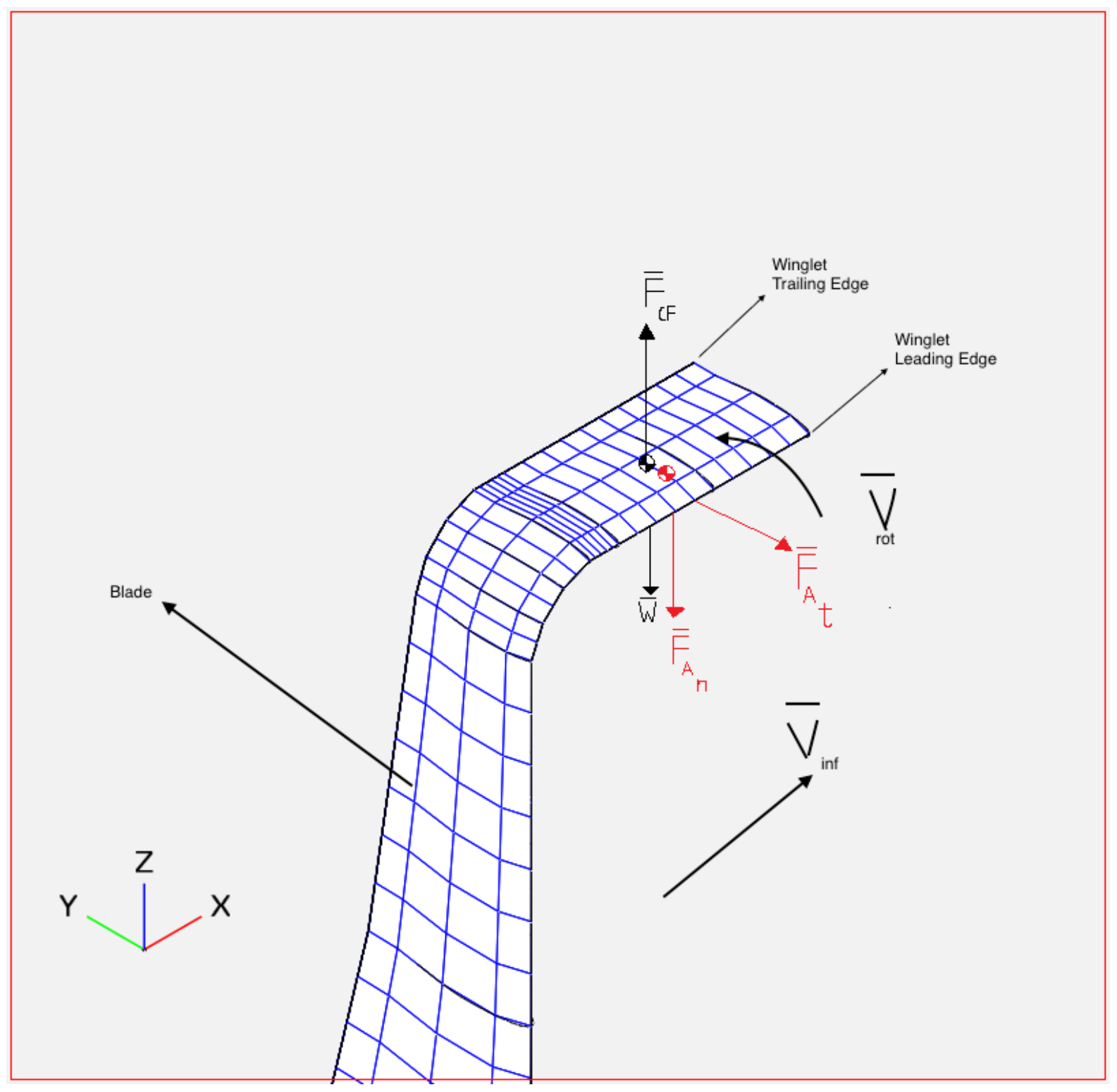

Figure 4.1 Freebody diagram of the winglet

\subsection{Sensitivity Study}

A sensitivity study has been performed to determine an optimum configuration for the winglet. It is carried out using the implemented vortex lattice method and by varying winglet parameters. Prior to beginning the design process, it is required to determine if the winglet 
should be bent towards the pressure side or the suction side of the blade. Johansen and Sørenson [25] show that while deflecting winglets to the suction side (downstream) may lead to tower clearance issues, aerodynamic efficiency obtained is greater. Additionally, pointing the winglets upstream means the wind turbine will be operating in its wake. Accordingly, the winglets designed in this study are designed to be deflected to the suction side.

Six parameters are generally considered in the winglet design process:

1. Airfoil

2. Winglet Height

3. Taper Ratio

4. Twist

5. Cant Angle

6. Sweep

As this is an initial study exploring the said design philosophy, only four parameters are varied. The effects of airfoil and sweep are not investigated in this study. It has been opted to use the same airfoil for the winglet that is used in the final blade section of the baseline NREL 5MW. For determining an optimum height and taper ratio, winglets at $0^{\circ}$ twist and $0^{\circ}$ cant angle have been tested at various heights and taper ratios. The baseline NREL 5MW has a rotor overhang of $5 \mathrm{~m}$, shaft tilt of $5^{\circ}$ and precone angle of $2.5^{\circ}$. With a maximum out of plane deflection of $5.5 \mathrm{~m}$ [18], tower clearance is calculated to be 5.148 meters. Maintaining a conservative approach, the maximum winglet height is restricted to half the tower clearance.

The sensitivity study shows benefit in using a winglet with a height of $1.9 \mathrm{~m}$, a radius of curvature of $0.5 \mathrm{~m}$. Subsequently, this configuration was used in each of the three designs. The optimum twist angle was determined to be $0^{\circ}$. These results are further discussed in Chapter 5. A detailed presentation of the sensitivity study is presented in Appendix A. 


\section{3 Design A}

Design A has been envisioned as a 'sleeve' winglet, essentially one that can be slipped onto the end of the turbine blade and adhesively bonded, negating a need for an adaptor or connector. Accordingly, the winglet is designed with a foam core embedded with a load bearing balsa spar. A chopped strand mat fiberglass skin wetted with resin forms a light shell that can bear loads. A thin layer of gel coat $(1.5$ mils $)$ provides a smooth finish. The winglet mass estimate is detailed in Table 7, while a breakdown of the components used, the quantity and their costs are presented in Table 8 . In order to prove that the designed winglet can withstand operational loads, basic structural analysis is done using strength of material techniques, determining tensile and compressive strengths of the winglet. Details on the structural analysis is presented in Appendix B.

TABLE 7

MASS ESTIMATE - WINGLET A

\begin{tabular}{|c|c|c|}
\hline Component & Required Quantity & Mass \\
\hline $\begin{array}{c}\text { Foamular® 150 Rigid XPS } \\
\text { Foam [26] }\end{array}$ & $0.5296 \mathrm{~m}^{3}$ & $11.03 \mathrm{~kg}$ \\
\hline Balsa Spar [27] & $1.9 \mathrm{~m}$ spar of $\phi=8 \mathrm{~cm}$ & $1.48 \mathrm{~kg}$ \\
\hline $\begin{array}{c}\text { E-Glass Chopped Strand } \\
\text { Mat } \\
\text { (US Composites 0.75 oz } \\
\text { CSM) [28] }\end{array}$ & $7.56 \mathrm{~m}^{2}$ & $1.73 \mathrm{~kg}$ \\
\hline $\begin{array}{c}\text { Polyester Resin } \\
\text { (US Composites 435 } \\
\text { Standard Polyester Resin) } \\
\text { [28] }\end{array}$ & 2.43 liter & $2.92 \mathrm{~kg}$ \\
\hline $\begin{array}{c}\text { Gel Coat } \\
\text { (US Composites Pure White } \\
\text { Gel Coat) [28] }\end{array}$ & 284 mL & $0.34 \mathrm{~kg}$ \\
\hline NET MASS OF ONE WINGLET & $\mathbf{1 7 . 5 ~ k g}$ \\
\hline
\end{tabular}


TABLE 8

NET COST - WINGLET A

\begin{tabular}{|c|c|c|}
\hline Component & Required Quantity & Cost \\
\hline $\begin{array}{c}\text { Foamular® } 150 \text { Rigid XPS } \\
\text { Foam [26] }\end{array}$ & $0.5296 \mathrm{~m}^{3}$ & $\$ 114$ \\
\hline Balsa Spar [27] & $1.9 \mathrm{~m} \mathrm{spar}$ of $\phi=8 \mathrm{~cm}$ & $\$ 47$ \\
\hline $\begin{array}{l}\text { E-Glass Chopped Strand } \\
\text { Mat } \\
\text { (US Composites } 0.75 \mathrm{oz} \\
\text { CSM) [28] }\end{array}$ & $7.56 \mathrm{~m}^{2}$ & $\$ 19$ \\
\hline $\begin{array}{c}\text { Polyester Resin } \\
\text { (US Composites } 435 \\
\text { Standard Polyester Resin) } \\
{[28]}\end{array}$ & 2.43 liter & $\$ 20$ \\
\hline $\begin{array}{c}\text { Gel Coat } \\
\text { (US Composites Pure White } \\
\text { Gel Coat) }[28]\end{array}$ & $284 \mathrm{~mL}$ & $\$ 5$ \\
\hline Labor for manufacture & 8 hours & $\$ 160$ \\
\hline Cost of 1 Winglet & 1 & $\$ 365$ \\
\hline $\begin{array}{c}\text { Labor for Installation (2 } \\
\text { Technicians) }\end{array}$ & 32 hours & $\$ 786$ \\
\hline Rental Cost - Service Lift & 32 hours & $\$ 786$ \\
\hline \multicolumn{2}{|c|}{ NET COST OF 3 WINGLETS } & $\$ 2,627$ \\
\hline
\end{tabular}

A model of Design A as attached to the blade is depicted in Figure 4.2.

Focusing on the simple nature of this winglet, all material is that which is locally available in Wichita, Kansas. Prices are current as of October 2016 in Wichita. All decimal values are rounded to the greatest integer value. Maintaining a conservative estimate, manufacturing time is set at 1 work day ( 8 hours), with an employee's salary set at $\$ 20$ per hour. Similarly, installation costs are calculated by assuming that it takes two technicians two work days to install three winglets, totaling 32 hours of labor, and require rental of a service 
lift. The US Bureau of Labor Statistics states that the average hourly salary for a wind turbine technician is $\$ 24.55$ [29]. As rental rates for service lifts are not readily available, the rate is set as equivalent to the hourly salary for a technician.

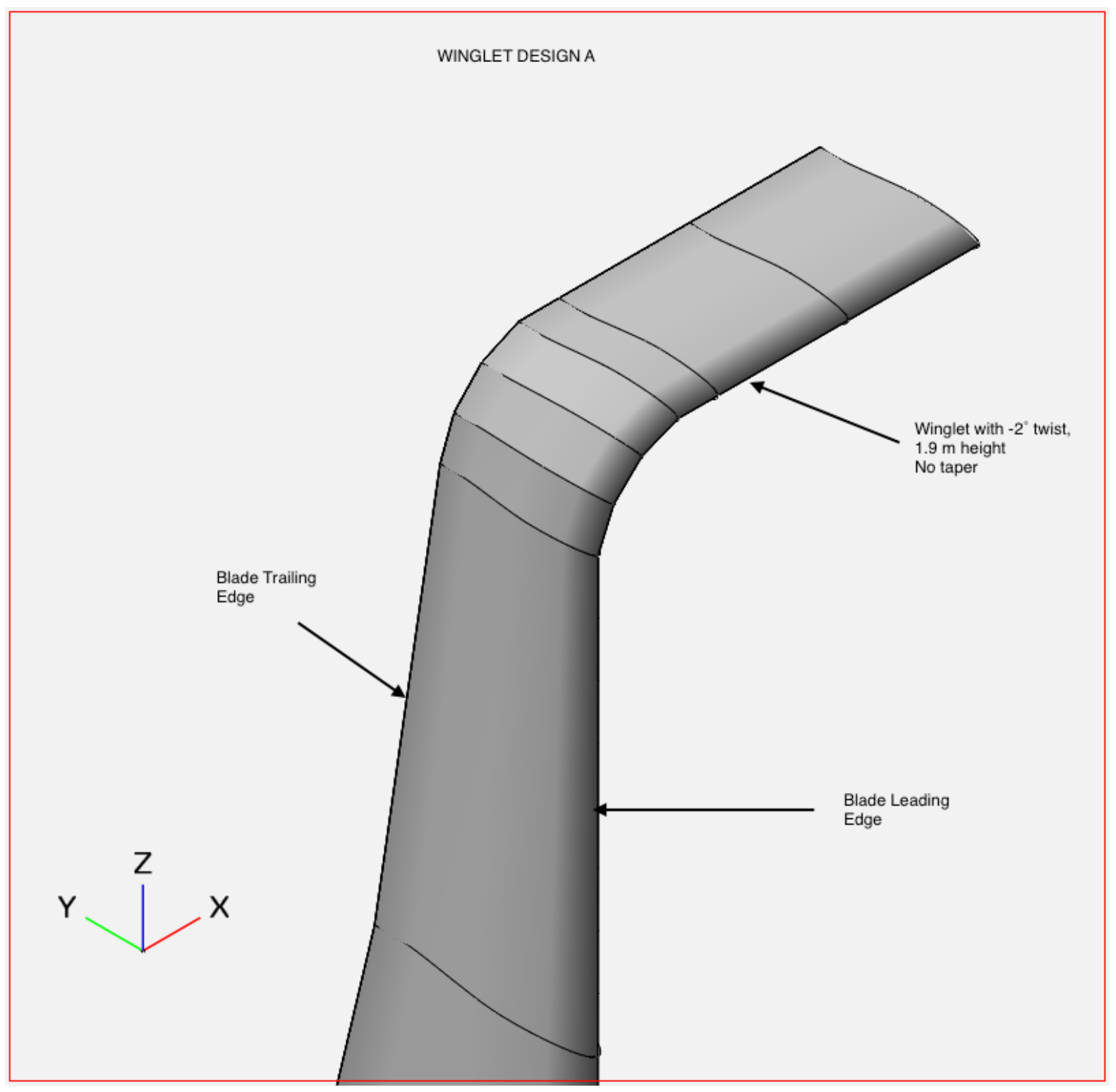

Figure 4.2. Winglet Design A

\subsection{Design B}

Design B preserves the basis of Design A: Foam core, fiberglass skin and balsa spar. The only marked difference is that more traditional connectors are designed using SAE 2024 
aluminum. Two circular female connectors of length $25 \mathrm{~cm}$ are embedded in the winglet at the quarter chord and three quarter chord points. The first connector (at the quarter chord point) is designed with an outer diameter of $10 \mathrm{~cm}$ and an inner diameter of $8 \mathrm{~cm}$. The second connector has an outer diameter or $6 \mathrm{~cm}$ and an inner diameter of $5 \mathrm{~cm}$. An adapter with two male connectors has been designed to be bolted on to the end of the wind turbine blade. A provision has been made on both sets of connectors to allow two 0.75 inch SAE 304 18-8 stainless steel bolts to hold the winglet in place. The bolts are designed to be in double shear. Figure 4.3 depicts a model of design B. Similar to model A, basic structural analysis has been performed to prove that the winglet can withstand operational loads. The cost breakdown of Design B is exactly the same as Design A, with the added cost of Al 2024 and added labor charges for metal work. Unlike metals like gold and silver, a commodity price for aluminum on the NASDAQ stock market is not available. Accordingly, the price of aluminum is considered to be that available in Wichita in October 2016, with a conservative margin applied $(\$ 2 / 1 \mathrm{~b}$ or $\$ 4.41 / \mathrm{kg}$ ). The mass estimate of Design B is presented in Table 9, while the net cost is presented in Table 10. It is assumed that it takes an additional 4 hours to manufacture one winglet of Design B, and an additional 2 hours to install three winglets of Design B. 
TABLE 9

MASS ESTIMATE - WINGLET B

\begin{tabular}{|c|c|c|}
\hline Component & Required Quantity & Mass \\
\hline $\begin{array}{c}\text { Foamular® 150 Rigid XPS } \\
\text { Foam }\end{array}$ & $0.5296 \mathrm{~m}^{3}$ & $11.03 \mathrm{~kg}$ \\
\hline $\begin{array}{c}\text { Balsa Spar } \\
\text { E-Glass Chopped Strand } \\
\text { Mat } \\
\text { (US Composites 0.75 oz } \\
\text { CSM) }\end{array}$ & $7.9 \mathrm{~m}$ spar of $\phi=8 \mathrm{~cm}$ & $1.48 \mathrm{~kg}$ \\
\hline $\begin{array}{c}\text { Polyester Resin } \\
\text { (US Composites 435 } \\
\text { Standard Polyester Resin) }\end{array}$ & 2.43 liter \\
\hline $\begin{array}{c}\text { Gel Coat } \\
\text { (US Composites Pure White } \\
\text { Gel Coat) }\end{array}$ & $284 \mathrm{~mL}$ \\
\hline Al 2024 & $2.92 \mathrm{~kg}$ \\
\hline NET MASS OF ONE WINGLET & $0.34 \mathrm{~kg}$ \\
\hline
\end{tabular}

TABLE 10

NET COST - WINGLET B

\begin{tabular}{|c|c|c|}
\hline Component & Quantity & Cost \\
\hline Cost of Design A & 1 & $\$ 365$ \\
\hline Al 2024 & $4.86 \mathrm{~kg}$ & $\$ 22$ \\
\hline $\begin{array}{c}\text { Additional Labor for } \\
\text { manufacture }\end{array}$ & 4 hours & $\$ 407$ \\
\hline $\begin{array}{c}\text { Cost of 1 Winglet } \\
\text { Labor for installation (2 } \\
\text { technicians) }\end{array}$ & 36 hours & $\$ 884$ \\
\hline $\begin{array}{c}\text { Rental Cost - Service Lift } \\
\text { NET COST FOR 3 WINGLETS }\end{array}$ & $\$ 884$ \\
\hline \multicolumn{2}{|c|}{} & 36 hours \\
\hline
\end{tabular}




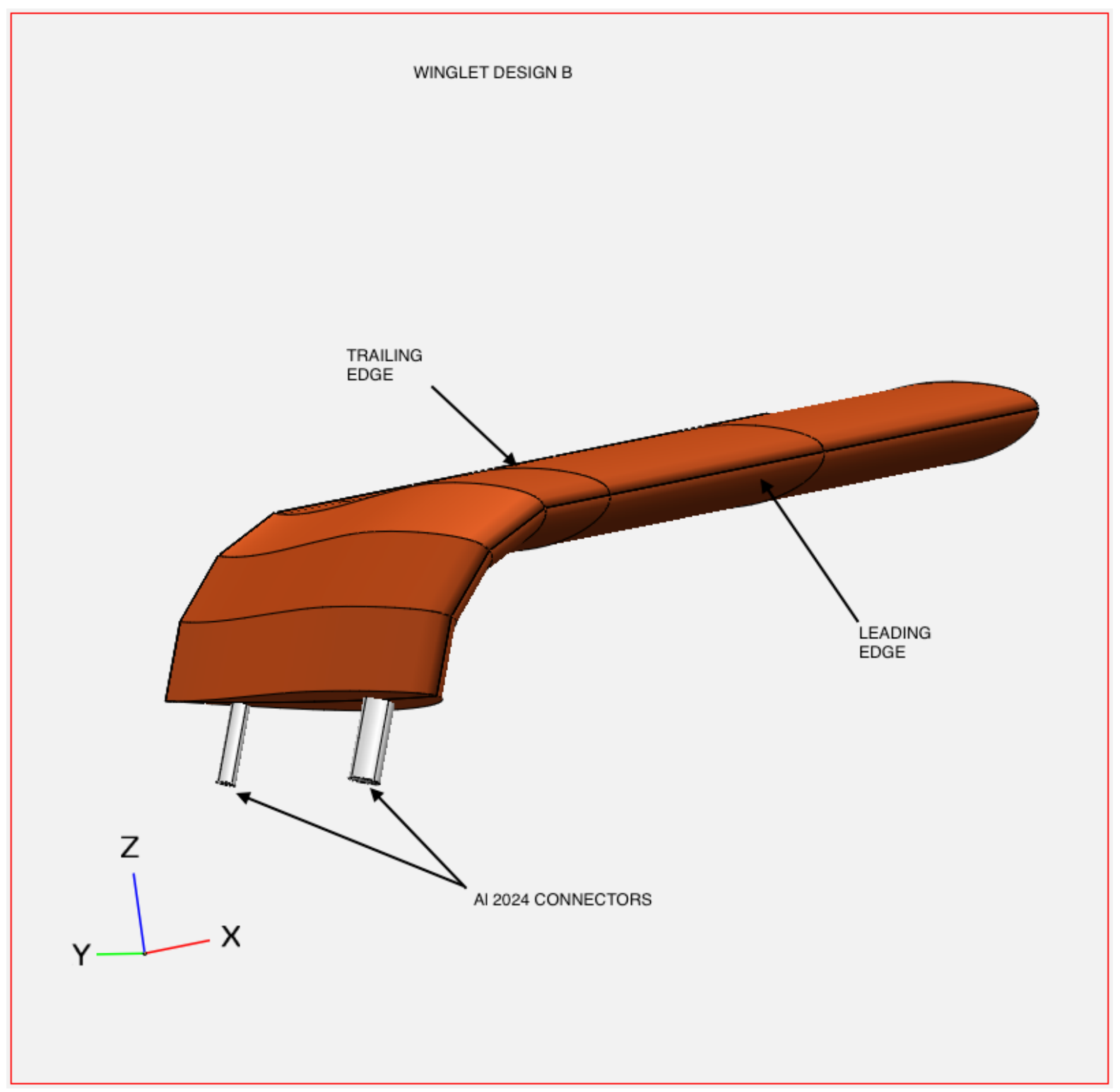

Figure 4.3. Winglet Design B with Al 2024 connectors at the end of the winglet

\subsection{Design $C$}

Design $\mathrm{C}$ reflects a more 'traditional' approach to winglet structure. For this design, it is assumed that the winglet is constructed in exactly the same manner as the main blade. To arrive at a mass estimate, a winglet mass density similar to the blade mass density at the blade tip listed in Jonkman et al [18] is used, that is, $10.32 \mathrm{~kg} / \mathrm{m}$. A cost estimate is arrived at by determining the cost per unit surface area of the main blade, and multiplying this by the surface area of the winglet. As the scaling relationship used to calculate cost of the main blade includes 
labor costs for manufacture, it is not necessary to compute this separately. The installation costs are considered the same as that of Design B. Table 12 reflects the net cost of Design C.

TABLE 11

MASS ESTIMATE - WINGLET C

\begin{tabular}{|c|c|c|}
\hline Mass per unit length & Total winglet length & Total mass \\
\hline $10.32 \mathrm{~kg}$ & $2.64 \mathrm{~m}$ & $\mathbf{2 7 . 3 4} \mathbf{~ k g}$ \\
\hline
\end{tabular}

TABLE 12

NET COST OF WINGLET - DESIGN C

\begin{tabular}{|c|c|c|}
\hline Component & Quantity & Cost \\
\hline Cost per unit surface area & $1 \mathrm{~m}^{2}$ & $\$ 604$ \\
\hline Cost for 1 winglet & $7.56 \mathrm{~m}^{2}$ & $\$ 4,567$ \\
\hline $\begin{array}{c}\text { Labor for installation (2 } \\
\text { technicians) }\end{array}$ & 36 hours & $\$ 884$ \\
\hline $\begin{array}{c}\text { Rental Cost - Service Lift } \\
\text { NET COST FOR 3 WINGLETS }\end{array}$ & $\mathbf{\$ 1 5 , 4 6 9}$ \\
\hline
\end{tabular}




\section{CHAPTER 5}

\section{RESULTS}

As has been stated previously, the design philosophy adopted in this thesis seeks not to merely offer an improvement in coefficient of power $\left(C_{p}\right)$, but attempt to balance the generated aerodynamic and centrifugal loads, and be economically viable. Simultaneously, it is sought to develop this winglet at minimum cost. A figure of merit has been developed that adequately demonstrates the best winglet design.

\subsection{Winglet Configuration}

The sensitivity study previously described yielded that for maximum benefit, a winglet designed for the NREL 5MW reference wind turbine should have a height of $1.9 \mathrm{~m}$, a radius of curvature of $0.6 \mathrm{~m}$, and no taper. This is established by observing which configuration offers the greatest improvement in $C_{p}$. With this configuration, various twist angles have been investigated. The objective with this set of iterations is to determine what twist angle offers maximum improvement in $C_{p}$, while being cognizant of the ratio of centrifugal force to the normal aerodynamic force. Since the baseline wind turbine exhibits maximum $C_{p}$ at an inflow speed of $8 \mathrm{~m} / \mathrm{s}$ and rotational speed of $\Omega=.9587 \mathrm{rad} / \mathrm{s}$, the winglets are tested at these conditions. A plot of improvement in $C_{p}$ against the ratio of forces for Design A is presented for in Figure 5.1. The sign convention adopted in Jonkman et al [18] is maintained.

While the efficacy of the implemented VLM has been demonstrated through comparison with established results, it is essential to keep in mind that these are theoretical results. The model does not take into account, for example, a free wake or increased roughness due to soiling of the blade. Accordingly, a threshold in improvement of $C_{p}$ has been established, below which the winglet design is disregarded even if normal and centrifugal forces are 
perfectly balanced. The selected threshold value is $2 \% \Delta C_{p}$, that is, unless a winglet offers an improvement of $2 \%$ in the coefficient of power, it is disregarded. This value is picked arbitrarily with the aim of accounting for assumptions made in implementing the VLM method. Although arbitrary, it is a conservative value, keeping with the approach of this thesis, and should account for any imperfections in the VLM method. Similarly, unless the ratio of normal aerodynamic force to centrifugal force is between 1 and 2.5, the winglet is disregarded. A ratio of less than 1 implies that the winglet is too heavy, while greater than 2.5 implies that the normal aerodynamic force is far greater than the centrifugal force, and the winglet would require unreasonable amounts of ballast to increase weight. The value of 1.5 leads to acceptable loads throughout the range of operation of the wind turbine.

Similar studies are done for Designs B and C, shown in Figures 5.2 and 5.3. As can be seen in all three plots, only three twist settings offer an increment in $C_{p}$ beyond the threshold value. While a twist of $-4^{\circ}$ consistently offers the highest increment in $C_{p}$, it can be seen that the ratio of normal aerodynamic force to centrifugal force is far too high to be acceptable. A twist setting of $-2^{\circ}$ offers good improvement in $C_{p}$, but when used with Design A, would require a fair amount of ballast to balance generated centrifugal and normal aerodynamic loads. Not twisting the winglet ( $0^{\circ}$ twist) only offers $2.43 \%$ improvement in $C_{p}$. However, since the ratio of forces is at an acceptable 1.76 for Design A and 1.38 for Design B, it implies minimal need for ballast or reinforcement. Accordingly, all further analyses are done with a twist configuration of $0^{\circ}$. 


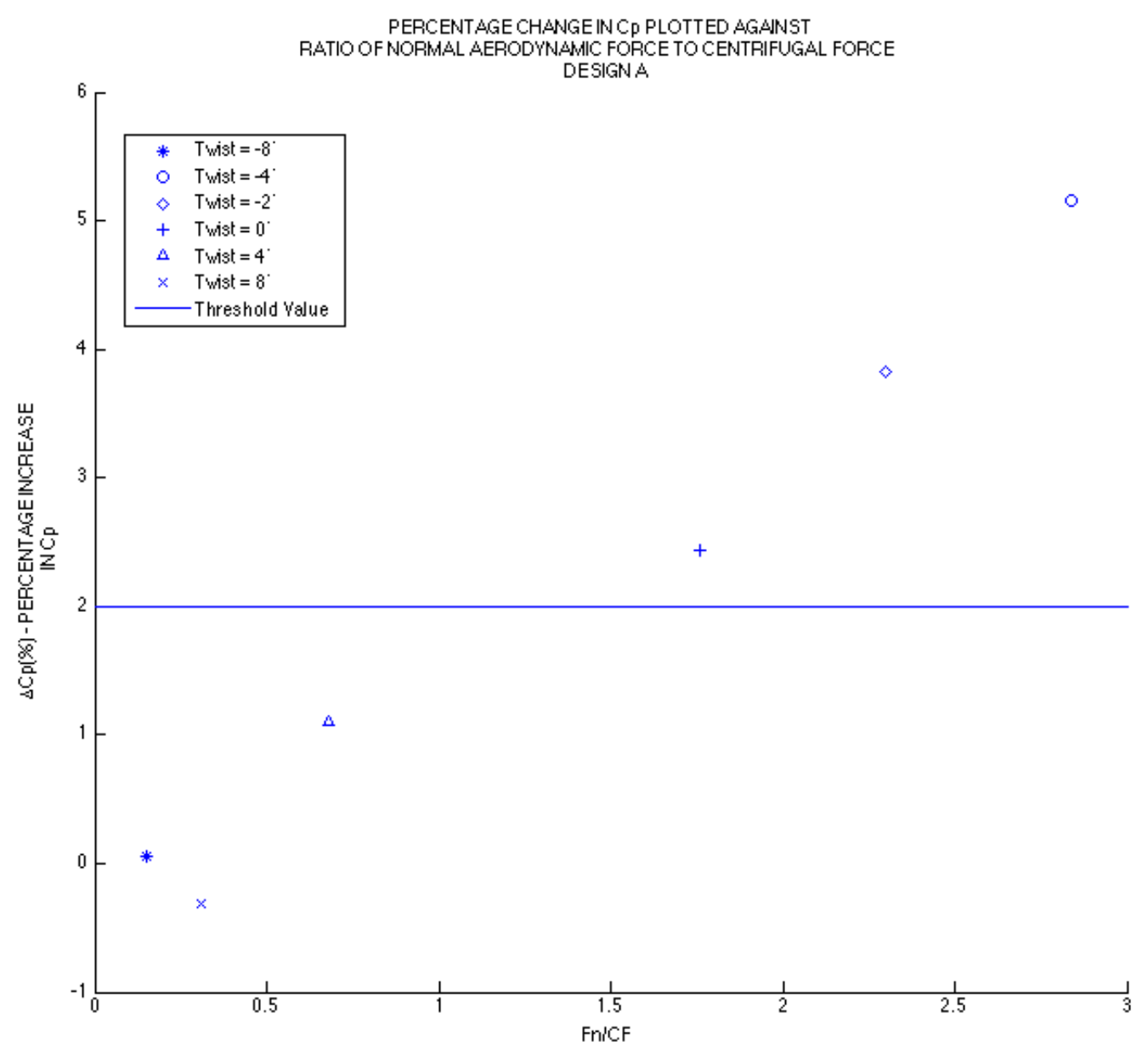

Figure 5.1 Percent change in $C_{p}$ plotted against the ratio of normal aerodynamic force to centrifugal force for Design A 


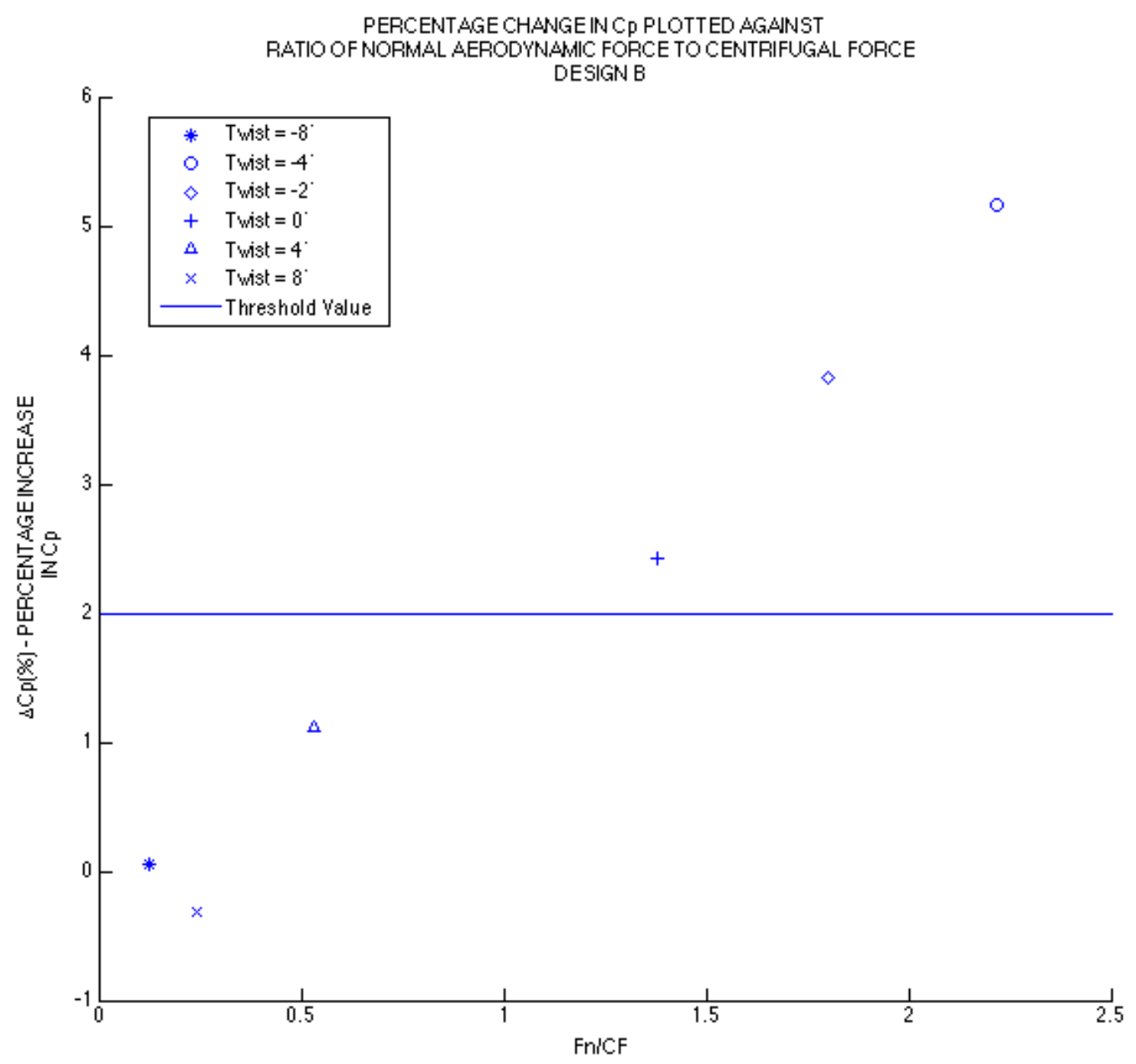

Figure 5.2 Percent change in $C_{p}$ plotted against the ratio of normal aerodynamic force to centrifugal force for Design $B$

A summary of the finalized winglet characteristics for Designs A, B and C is presented in Table 13. This winglet configuration is used to determine the net increase in AEP, as well as figure of merit for each Design in the following sections. 


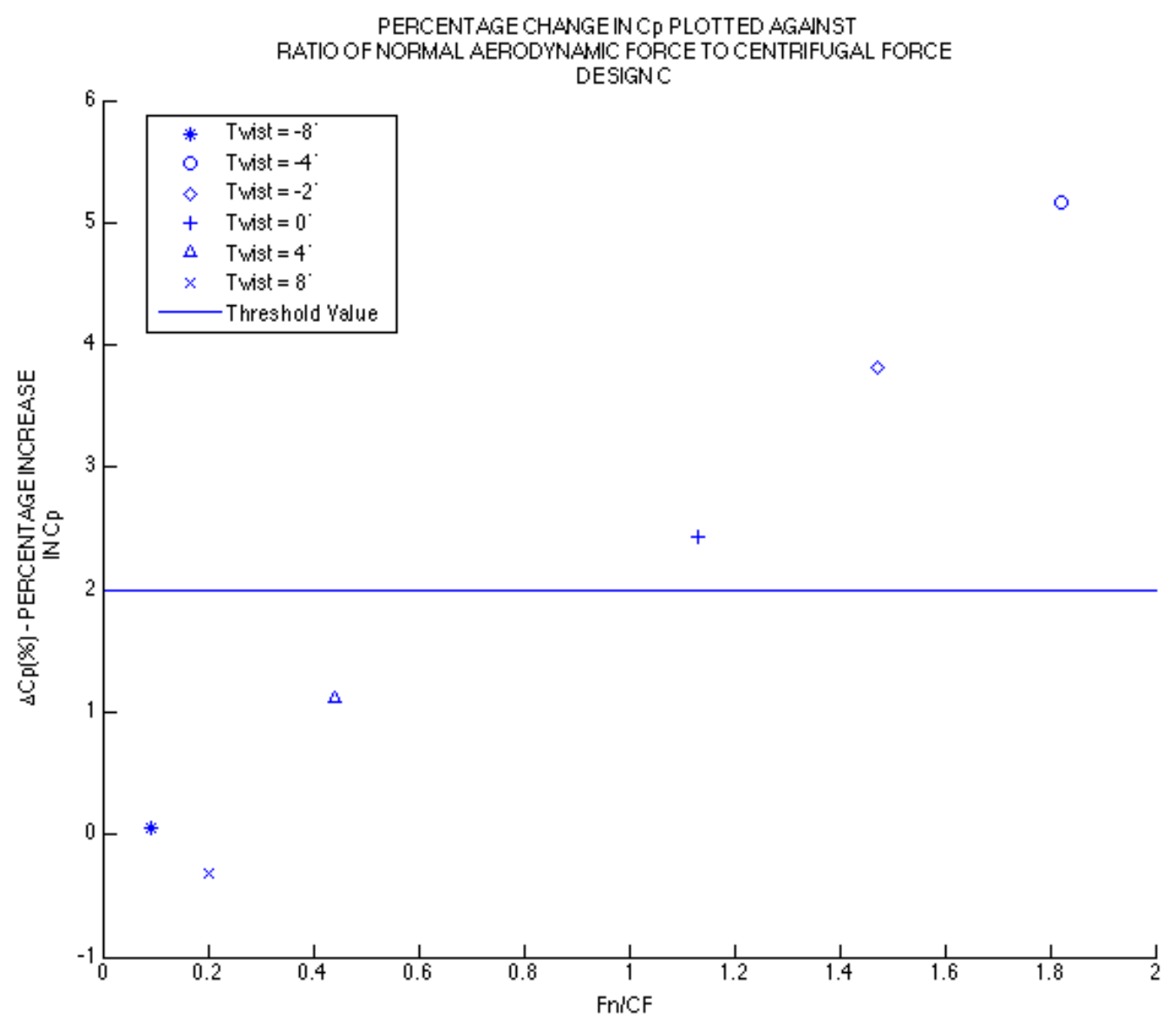

Figure 5.3 Percent change in $C_{p}$ plotted against the ratio of normal aerodynamic force to centrifugal force for Design $\mathrm{C}$

TABLE 13

FINAL WINGLET CHARACTERISTICS

\begin{tabular}{|c|c|}
\hline Twist & $0^{\circ}$ \\
\hline Taper ratio & 1 \\
\hline Height & $1.9 \mathrm{~m}$ \\
\hline Radius of Curvature & $0.5 \mathrm{~m}$ \\
\hline
\end{tabular}




\subsection{Effect on Circulation}

The change in circulation over the main blade span is depicted in figure 5.4. As expected, the addition of winglets leads to a decrease in shed vorticity, pushing up the circulation distribution along the blade span. This additional circulation leads to an increase in blade tangential forces, resulting in an increase in $C_{p}$.

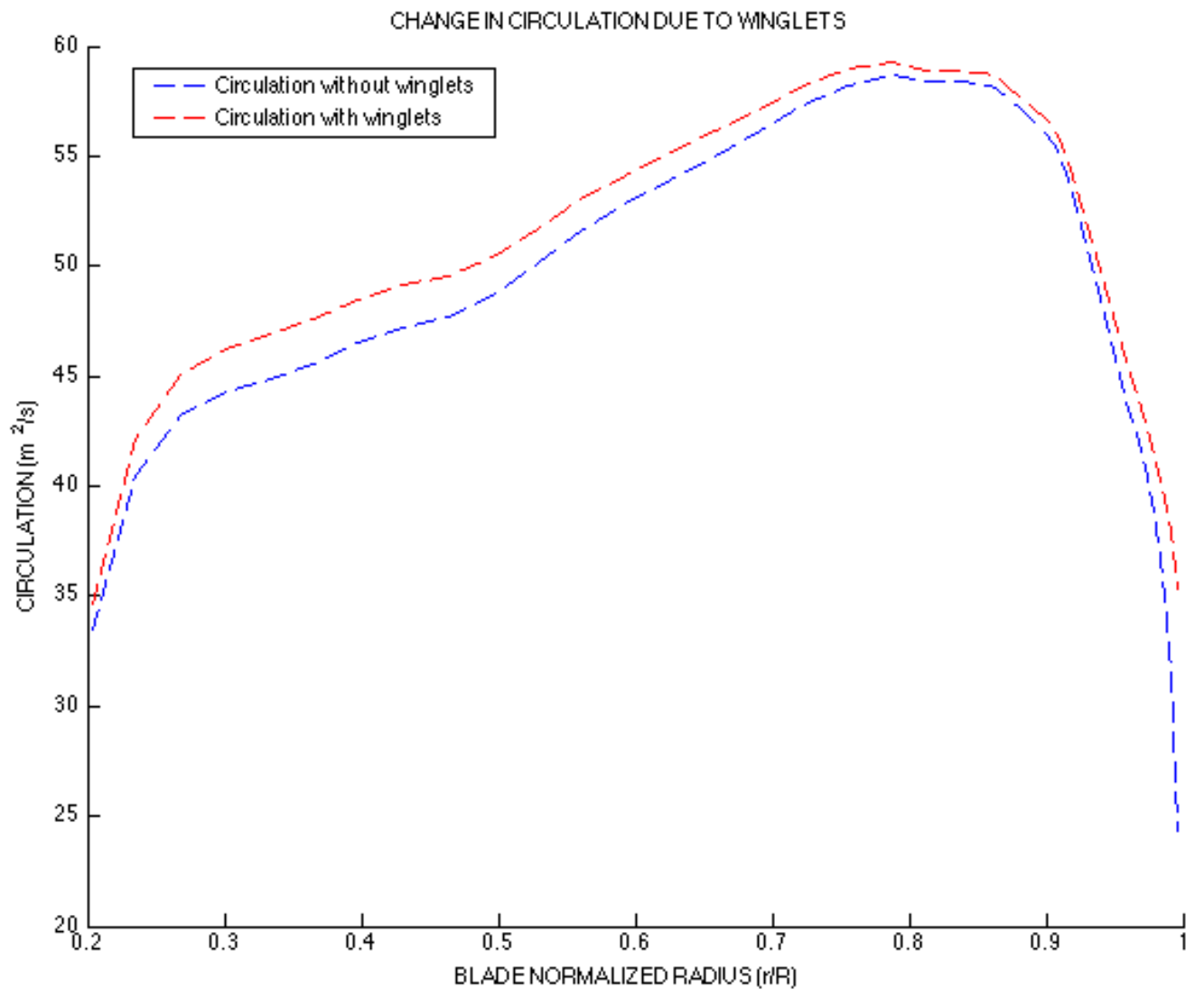

Figure 5.4. Change in circulation due to the addition of winglets.

\subsection{Change in Annual Energy Production}

Using the winglet described in Table 13, the increment in AEP is calculated. In order to ascertain a monetary value of the benefit, the average cost per unit of electricity is considered. The United States Energy Information Administration lists the average cost of electricity in the US for the month of August 2016 as $\$ 0.1083 / \mathrm{kWh}$ [30], leading to an increase in revenue of $\$ 40,046$. 
TABLE 14

INCREMENT IN ANNUAL ENERGY PRODUCTION

\begin{tabular}{|c|c|}
\hline $\mathrm{C}_{\mathrm{p}}$ without Winglets & 0.5134 \\
\hline AEP without Winglets & $21,777.14 \mathrm{MWh}$ \\
\hline $\mathrm{C}_{\mathrm{p}}$ with Winglets & 0.5260 \\
\hline AEP with Winglets & $22,146.90 \mathrm{MWh}$ \\
\hline Change in AEP & $\mathbf{+ 3 6 9 . 7 6} \mathbf{M W h}$ \\
\hline Increase in Revenue (at $\mathbf{\$ 0 . 1 0 8 3 / \mathbf { k W h } )}$ & $\mathbf{\$ 4 0 , 0 4 6}$ \\
\hline
\end{tabular}

To determine the return on investment generated by the employment of winglets, the cost of manufacturing and installing the winglet is subtracted from the increase in revenue. The final results for each winglet design is presented in Table 15.

TABLE 15

ANNUAL RETURN ON INVESTMENT ON VARIOUS WINGLET DESIGNS

\begin{tabular}{|c|c|c|}
\hline Winglet Design & Net Profit per year & New LCOE \\
\hline Design A & $\$ 37,419$ & $\$ 0.03307 / \mathrm{kWh}$ \\
\hline Design B & $\$ 36,917$ & $\$ 0.03309 / \mathrm{kWh}$ \\
\hline Design C & $\$ 24,577$ & $\$ 0.03365 / \mathrm{kWh}$ \\
\hline
\end{tabular}

\subsection{Figure of Merit}

The additional revenue generated by installing winglets has been addressed in Section 5.2. To present this in a more simplified manner, and in order to make holistic comparisons, a Figure of Merit (FOM) is devised. The figure of merit is the ratio of the change in percentage of the coefficient of power $\left(\Delta \% C_{p}\right)$ to the cost of manufacturing and installing the winglet $(\Delta \$$ in thousands). All three winglet designs (A, B and C) use the characteristics outlined in Table 
14. For the optimum winglet design, it was sought that the FOM be maximum (implying maximum increase in $C_{p}$ at minimum cost), while ensuring that the ratio of normal aerodynamic force to centrifugal force be as close to 1.5. The results are presented in Figure 5.5. It can be seen that Design A offers the highest FOM of all three designs when forces are close to balanced.

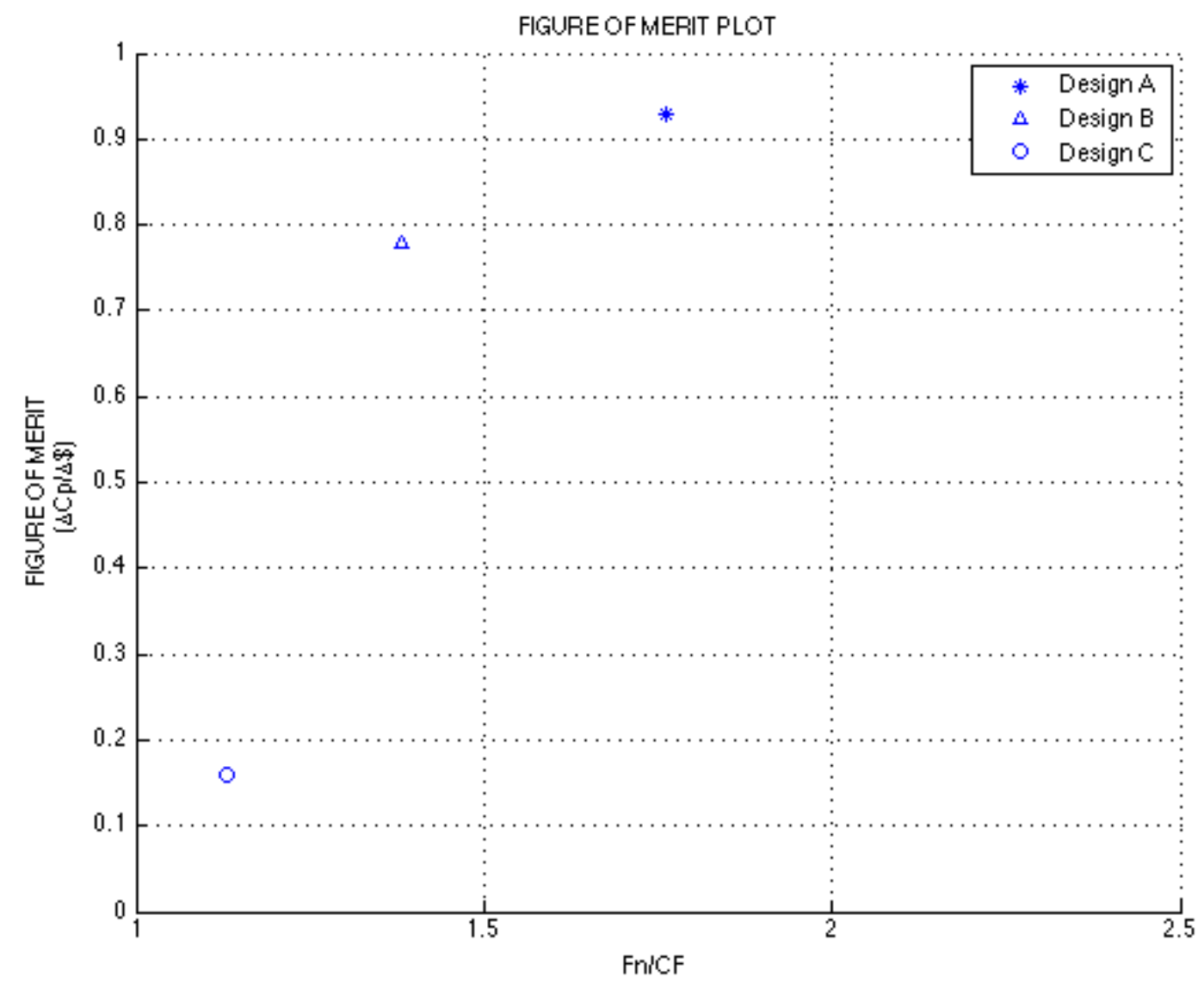

Figure 5.5. Figure of Merit $(\Delta \mathrm{Cp} / \Delta \$)$ plotted against the ratio of Normal Aerodynamic Force to Centrifugal Force for Design $\mathrm{C}$

\subsection{Increase in Thrust}

Reduction in tip effects and increase in circulation distribution are the desired results of winglets in wind turbines. However, reduction in tip effects also means the component of force generated in the direction normal to the blade is larger than without winglets. In wind turbines, this force is termed as thrust. For the conventional aerodynamicist, it is possible to 
follow Stoddard and Eggleston's approach to understanding thrust. Equating a wind turbine to a flat rotor disk, it is possible understand the thrust as the drag force acting on the flat plate with area equal to that of the rotor disk [2]. Similar to the manner in which a drag coefficient is defined, it is possible to define the coefficient of thrust $\left(C_{T}\right)$ as:

$$
C_{T}=\frac{T}{q A}
$$

Here, $T$ is the thrust force generated by the wind turbine, $q$ is the dynamic pressure and $A$ is the rotor disk area.

Large increases in thrust are not desirable, as they yet again would demand a stronger blade to withstand added moments. The net thrust per blade with and without winglets, and the increase in thrust in shown in Table 16. As can be seen, the chosen winglet configuration leads to an increase in thrust of $1 \%$.

TABLE 16

EFFECT ON THRUST DUE TO THE USE OF WINGLETS

\begin{tabular}{|c|c|c|}
\hline $\begin{array}{c}\text { Thrust per blade with } \\
\text { winglets (N) }\end{array}$ & $\begin{array}{c}\text { Thrust per blade without } \\
\text { winglets (N) }\end{array}$ & Percentage increase \\
\hline 129,463 & 128,179 & $1.00 \%$ \\
\hline
\end{tabular}




\section{CHAPTER 6}

\section{CONCLUSIONS}

The objective of this thesis has been to demonstrate and provide a proof of concept of retrofit winglets for wind turbines, using a novel design philosophy. In exploring the retrofit aspect, it is sought to improve the maximum power coefficient of the thousands of wind turbines currently in operation using the devised winglet. Emphasis has been laid on designing a winglet that balances generated normal aerodynamic load, centrifugal load and weight, leading to a winglet that does not lead to unacceptable increases in blade root bending moment. This allows a light, cheap winglet that does not require the main blade to be structurally reinforced to support it, and is economically feasible.

In conclusion, a concise summary of the findings of this study can be presented:

- A vortex lattice method has been written and implemented in MATLAB. It is found that the results compared well with previously published and validated results.

- A design philosophy centered around constructing light winglets and balancing generated loads has been adopted. For the NREL 5MW reference wind turbine, a winglet configuration with a height of $1.9 \mathrm{~m}$, radius of curvature of $0.5 \mathrm{~m}$, no taper and twist of $0^{\circ}$ is found to be optimum.

- The adopted winglet configuration leads to an increase of $2.43 \%$ in the maximum coefficient of power.

- All three winglet designs proposed are found to be economically viable.

- It is found that Design A offers the most economic benefit, with an annual profit of $\$ 37,419$ per year. Designs B and C offers an annual profit of $\$ 36,917$ and $\$ 24,577$ respectively. 


\section{CHAPTER 7}

\section{RECOMMENDATIONS FOR FUTURE WORK}

This study has demonstrated the benefit and viability of retrofit winglets for wind turbines. As with any research project, there is always scope to build further on the initial findings presented here. A few recommendations for future work are:

- Optimization of winglet design: To arrive at the optimum winglet configuration, winglet height, taper ratio and cant angle are varied manually and their effect on $C_{p}$ is studied. An optimization algorithm would be a far more effective process in selecting winglet design, while also taking into account effect of winglet sweep and airfoil.

- Effect of winglet sweep: The effect of winglet sweep is not investigated here. Investigating sweep may lead to a winglet that offers greater benefit while continuing to ensure forces in consideration are balanced.

- Airfoil: The airfoil used in the winglet is the same as the airfoil at the blade tip of the baseline wind turbine. Designing (or selecting) an airfoil tailored for a winglet may lead to further improvement in $\Delta C_{p}$.

- Effect of wake: A prescribed wake is used in this model, and is sufficient to demonstrate the effect of winglets on wind turbines. Using a free wake may lead to improved accuracy.

- Effect of thrust: While the increase in thrust is quantified, the effect of increased thrust values due to the use of winglets has not been thoroughly investigated. Further studies should determine what increase in the thrust coefficient $\left(C_{t}\right)$ is acceptable from a structural stand point. 
- Experimental Results: This study has performed the first step of establishing theoretically that retrofit winglets are a sound and viable proposition. A logical next step is to validate this with experimental results.

- Cost Estimates: All cost data reflected in this thesis is built on estimates of materials available in the market as of October 2016, as well as information from the US Bureau of Labor Statistics [29] and the US Energy Information Administration [30]. It is important to be cognizant of the fact that conclusions drawn in this thesis are prone to variation due to fluctuations in cost.

- Acoustic Effects: As wind turbine rotor diameters routinely increase in size, the noise generated by wind turbines is an important consideration in the design process. Acoustic effects of attaching retrofit winglets have not been explored in this study. Given that winglets lead to smaller blade tip vortices, it can be expected that attaching retrofit winglets actually leads to a reduction in the noise generated. Quantifying this effect is an avenue of study for future projects.

- Bird Strikes: The contribution of wind turbines to bird fatalities is an area of much contention. Nevertheless, it is important to quantify if the addition of retrofit winglets poses any additional risk to birds. This is yet another avenue for future studies.

- Farm Siting: The effect of retrofit winglets on a single wind turbine has been investigated. If the addition of winglets on wind turbines will adversely affect the power producing capabilities of other wind turbines in a wind farm is an area that must be thoroughly studied.

- Application to other wind turbines: Wind turbines of smaller wattage ('micro wind turbines') are finding much application today. While the effect of retrofit winglets on a large wind turbine of diameter over one hundred meters has been shown, the application of this design philosophy to smaller winglets is a subject that merits further 
investigation. Of interest is the question of whether retrofit winglets on small wind turbines will be economically feasible. 
REFERENCES 


\section{REFERENCES}

[1] "Global Wind Report 2015," Global Wind Energy Council, 2015.

[2] Eggleston, D. M., Stoddard, F. S., Wind Turbine Design Engineering, $1^{\text {st }}$ ed., Van Nostrand Reinhold Company Inc., New York, 1987.

[3] Hansen, M.O.L., Aerodynamics of Wind Turbines, $2^{\text {nd }}$ ed. Earthscan, 2008.

[4] Wilson, R.E., Lissaman, P.B.S., "Applied Aerodynamics of Wind Power Machines," Oregon State University, National Science Foundation, Research Applied to National Needs (RANN), Grant No. GI-418340, May 1974.

[5] Abedi, Hamidreza. "Development of Vortex Filament Methods for Wind Turbine Aerodynamic Loads on Rotor Blades," Thesis for Licentiate of Engineering, Department of Applied Mechanics, Chalmers University of Technology, Gothenburg, Sweden, 2013.

[6] Gyatt, G.W., Lissaman, P.B.S., "Development and Testing of Tip Devices for Horizontal Axis Wind Turbines,” NASA CR-174991, May 1985.

[7] Van Bussel, G.J.W., "A Momentum Theory for Winglets on Horizontal Axis Wind Turbine Rotors and some comparison with experiments," Fourth IEA Symposium on the Aerodynamics of Wind Turbines, Rome, Italy, November 1990.

[8] Imamura, H., Hasegawa, H., Kikuyama, K., "Numerical Analysis of the Horizontal Axis Wind Turbine with Winglets," JSME International Journal, Series B vol. 41, pp 170-176., Feb. 1998.

[9] Gaunaa, M., Johansen, J., "Can $\mathrm{C}_{\mathrm{p}}$ be increased by the use of winglets? - or - A Theoretical and Numerical Investigation of the Maximum Aerodynamic Efficiency of Wind Turbine Rotors with Winglets," $46^{\text {th }}$ Aerospace Sciences Meeting and Exhibit, Reno, Nevada, January 2008; Also AIAA Paper 2008-1314.

[10] Johansen, J., Sørenson, N.N., "Numerical Analysis of Winglets on Wind Turbine Blades using CFD," Proceedings of the 2007 European Wind Energy Conference and Exhibition, Madrid, Spain, 2007.

[11] "Renewable Energy Technologies Cost Analysis Series: Wind Power," Vol. 1, Issue 5, International Renewable Energy Agency, June 2012.

[12] Katz, J., Plotkin, A., Low Speed Aerodynamics: From Wing Theory to Panel Methods, $1^{\text {st }}$ ed., McGraw-Hill Inc., 1991.

[13] Phillips, W.F., Snyder, D.O., "Modern Adaptation of Prandtl's Classic Lifting Line Theory," Journal of Aircraft, Vol.37, No. 4, Jul-Aug 2000.

[14] van Garrel, A. "Development of a Wind Turbine Aerodynamics Simulation Module," ECN-C-03-079, August 2003. 
[15] Abedi, H., Davidson, L., Voutsinas, S., "Vortex Method Application for Aerodynamic Loads on Rotor Blades,” EWEA: Europe's Premier Wind Energy Conference, 2013.

[16] MATLAB Release R2014a, The Mathworks Inc., Natick, Massachusetts, United States.

[17] McDonald, R., “OpenVSP,” www.openvsp.org [retrieved 7 October 2015].

[18] Jonkman, J., Butterfield, S., Musial, W., Scott, G., "Definition of a 5-MW Reference Wind Turbine for Offshore System Development," NREL/TP-500-38060, Feb. 2009.

[19] Marten, D., Wendler, J., Pechlivaoglou, G., Nayeri, C.N, Pascherit, C.O., "QBlade: An Open Source Tool for Design and Simulation of Horizontal Axis Wind Turbines," International Journal of Emerging Technology and Advanced Engineering, Vol. 3, Special Issue 3, Feb. 2013.

[20] Fingersh, L., Hand, M., Laxson, A., "Wind Turbine Design Cost and Scaling Model," NREL/TP-500-40566, December 2006.

[21] Jong, Mark T., Thoman, Gary C., "Wind Characteristics for the Western Part of Kansas," Wind Energy Report No. 4, Wind Energy Laboratory, Wichita State University, Wichita, KS. Feb 1978.

[22] Carillo, C., Montano, A.F.O, Cidras, J., Diaz-Dorado, E., "Review of Power Curve Modelling for Wind Turbines," Renewable and Sustainable Energy Reviews, Vol. 21, Feb. 2013.

[23] "Consumer Price Index Inflation Calculator," US Bureau of Labor Statistics, http://www.bls.gov/data/inflation_calculator.htm [retrieved 15 October 2016].

[24] Frost, W., Long, B.H., Turner, R.E., "Engineering Handbook on the Atmospheric Environmental Guidelines for Use in Wind Turbine Generator Development," NASA TP1359, 1978.

[25] Johansen, J., Sørenson, N.N, “Aerodynamic Investigations of Winglets on Wind Turbine Blades using CFD,” Risø-R-1543(EN), Risø National Laboratory, Roskilde, Denmark, Feb 2006.

[26] "Foamular 150 Rigid Foam Insulation," Owens Corning, http://www.foamular.com/foam/products/foamular-150.aspx [retrieved 15 October 2016].

[27] "Balsa Blocks," National BalsaCompany, http://www.nationalbalsa.com/Balsa_Blocks_s/49.htm [retrieved 15 October 2016].

[28] "Product Index," US Composites, Inc. West Palm Beach, FL., http://www.uscomposites.com/products.html [retrieved 15 October 2016].

[29] "Occupational Outlook Handbook," US Bureau of Labor Statistics, Dec. 2015, http://www.bls.gov/ooh/installation-maintenance-and-repair/wind-turbine-technicians.htm [retrieved 15 October 2016]. 
[30] "Electric Power Monthly with Data for August 2016," US Energy Information Administration, October 2016.

[31] "Diab Probalsa," Diab International AB, http://www.diabgroup.com/Products-andservices/Core-Material/ProBalsa [retrieved 18 September 2016]. 
APPENDICES 


\section{APPENDIX A}

\section{SENSITIVITY STUDY FOR OPTIMAL WINGLET DESIGN}

In order to arrive at optimum winglet height, taper ratio and cant angle, a sensitivity study has been carried out. For the sensitivity study, the NREL 5MW reference wind turbine is tested with winglets of varying height at conditions of $\bar{v}_{\infty}=8 \mathrm{~m} / \mathrm{s}$ and $\Omega=0.9587 \mathrm{rad} / \mathrm{s}$ using the implemented vortex lattice method and their effect on $C_{p}$ is analyzed. A height is chosen when further increases in height do not offer appreciable increase in $C_{p}$. Having selected a height, a range of taper ratios and cant angles are explored, with maximum increase in $C_{p}$ again being the objective.

TABLE A1

VARIATION OF $C_{P}$ WITH WINGLET HEIGHT

\begin{tabular}{|c|c|}
\hline Winglet Height $(\mathrm{m})$ & Coefficient of Power \\
\hline No winglet & 0.5134 \\
\hline 1.45 & 0.5246 \\
\hline 1.6 & 0.5248 \\
\hline 1.75 & 0.5251 \\
\hline 1.9 & 0.5254 \\
\hline 2.2 & 0.5259 \\
\hline
\end{tabular}

Beyond $1.9 \mathrm{~m}$, the increase in height is not proportional to the increase in $C_{p}$. Accordingly, 1.9 $\mathrm{m}$ is the selected height for the winglet. Using this height, various taper ratios are investigated for the winglet. 
TABLE A2

VARIATION OF $C_{P}$ WITH TAPER RATIO

\begin{tabular}{|c|c|}
\hline Taper Ratio & Coefficient of Power \\
\hline 1 & 0.5254 \\
\hline 0.7 & 0.5253 \\
\hline 0.5 & 0.5252 \\
\hline
\end{tabular}

Decreasing taper ratio leads to a drop in $C_{p}$, so a taper ratio of one is used for the final iteration. Cant angles close $0 \mathrm{f} 80^{\circ}, 85^{\circ}$ and $90^{\circ}$ are investigated. It is necessary to maintain this slim range of cant angles to stick to the design philosophy, that is, balance generated centrifugal load, normal aerodynamic load and weight. Varying cant angle does not lead to appreciable increase in $C_{p}$, so a cant angle of $90^{\circ}$ is used. 


\section{APPENDIX B}

\section{BASIC STRUCTURAL ANALYSIS}

A preliminary analysis using basic strength of materials relationships is done to quantify the strength of the designed winglet. Designs A and B use an identical structure, with a foam core, a load bearing balsa spar and a chopped strand mat fiberglass skin. Design B also has additional aluminum (Al 2024) connectors.

\section{B1. Foamular ${ }^{\circledR} 150$ Rigid XPS Foam}

The material properties of Foamular ${ }^{\circledR} 150$ Rigid XPS Foam is available in literature published by the manufacturer [26]. This foam has a density of $20.82 \mathrm{~kg} / \mathrm{m}^{3}$, and a compressive strength of $103 \mathrm{kPa}$.

\section{B2. Balsa Spar}

The employed Balsa spar has a diameter of $8 \mathrm{~cm}$. National Balsa Company does not provide tensile and compressive strength values for its products. Values from Diab Probalsa [31] are used, as they reflect experimental values and are commonly used in wind turbine applications. The published values of compressive strength for Probalsa is $12.1 \mathrm{MPa}$ and tensile strength is $13.5 \mathrm{MPa}$.

Keeping up with the conservative approach used in this thesis, the maximum bending stress faced by the winglet is computed by assuming half the maximum load acts only at the spar tip, leading to a large value of bending moment. In reality, the load is distributed along the spar, so this approach works in a large factor of safety. For design A: 
TABLE B1

MAXIMUM LOAD AT RATED SPEED

\begin{tabular}{|c|c|c|}
\hline Weight & Maximum Normal & Maximum Centrifugal Load \\
& Aerodynamic Load & \\
\hline $155.38 \mathrm{~N}$ & $1784.02 \mathrm{~N}$ & $975.67 \mathrm{~N}$ \\
\hline
\end{tabular}

So the maximum bending stress calculated is:

$$
\sigma=\frac{B M \cdot y}{I}
$$

Using the dimensions of the balsa spar and the calculated loads, the maximum bending stress is calculated as $11.62 \mathrm{MPa}$.

\section{B3. Fiberglass Skin}

To calculate the strength of the fiberglass composite, a volume fraction of 50/50 is used. Thus, the tensile modulus of the composite is calculated as:

$$
\text { Tensile modulus of composite }=V_{f} E_{f}+V_{r} E_{r}
$$

Here, $E_{f}$ and $E_{r}$ are values of tensile modulus for the fiber and resin respectively. They are obtained from the manufacturer [28]. The computed tensile modulus for the composite is 45.04 GPa. To determine the strength of the composite, the strain at failure is computed for the resin and fiber, and the one which fails first dictates the tensile strength of the composite.

$$
\begin{gathered}
\varepsilon_{f}=\frac{\sigma_{f}}{E_{f}} \\
\varepsilon_{r}=\frac{\sigma_{r}}{E_{r}}
\end{gathered}
$$

It is seen that the resin has a lower strain of failure at 0.0161 . So the tensile strength of the composite is calculated as:

$$
\text { (Tensile modulus of composite) } \times \text { (strain at failure of resin) }
$$

The tensile strength of the composite is calculated as $0.725 \mathrm{GPa}$. 


\section{B4. Connectors for Design B}

As mentioned in the text, the connectors in design B utilize two SAE 304 stainless steel bolts in double shear to attach the winglet to the blade. The tensile strength of SAE 304 stainless steel is $585 \mathrm{MPa}$, while its ultimate yield strength is $240 \mathrm{MPa}$. The calculated ultimate tensile and yield strengths are $68.77 \mathrm{kN}$ and $167.03 \mathrm{kN}$ respectively. The shear strength of the bolts are $100.22 \mathrm{kN}$, and since the bolts are in double shear, the shear strength is calculated as 200.44 $\mathrm{kN}$. 